\title{
Analysis of Waste-Rock Transportation Process Performance in an Open-Pit Mine Based on Statistical Analysis of Cycle Times Data
}

\author{
Samwel Victor Manyele \\ Department of Chemical and Mining Engineering, College of Engineering and Technology, University of Dar es Salaam, \\ Dar es Salaam, Tanzania \\ Email: smanyele@udsm.ac.tz
}

How to cite this paper: Manyele, S.V. (2017) Analysis of Waste-Rock Transportation Process Performance in an Open-Pit Mine Based on Statistical Analysis of Cycle Times Data. Engineering, 9, 649-679. https://doi.org/10.4236/eng.2017.97040

Received: May 12, 2017

Accepted: July 21, 2017

Published: July 24, 2017

Copyright $\odot 2017$ by author and Scientific Research Publishing Inc. This work is licensed under the Creative Commons Attribution International License (CC BY 4.0).

http://creativecommons.org/licenses/by/4.0/

\begin{abstract}
In this paper, the performance of a waste rock transportation process in an open pit mine was assessed by using cycle time data. A computerized truckexcavator dispatch system was used to record the cycle times. The process was broken into seven steps (or components of the total cycle), durations of which were recorded for a period of 1 month, leading to $N=60,690$ data points or dispatches. The open pit mine studied consisted of 12 waste types loaded by 14 excavators and hauled by 49 trucks (at a trucks-to-excavator ratio of 3.5:1) in 75 changing locations. The string-type data was coded using integers to allow a FORTRAN code to extract process performance parameters using statistical analysis. The study established a wide range of parameters including: the waste material generation rate (about 1.73 million $t / m o n t h, 81 \%$ comprising waste rock), truck fill factor, $f$, total cycle time $\left(T_{c t}\right)$, production capacity, theoretical cycle time, non-productive cycle time $T_{n p}$, and cycle time performance ratio (CTPR), denoted as $T_{p r}$ The factors affecting the process performance include: truck model, excavator model, location (haul distance and road conditions) and material type. For a fixed material type and tonnage, the PDFs of the cycle time components were logarithmic in nature, capable of differentiating performance variations under different factors. It was concluded that the performance of the waste material transportation system in this mine was determined to be acceptable due to mean value of $T_{p r}=2.432$ being closer to unity. Reduction measures were suggested to minimize the cycle time for the process bottlenecks determined from Pareto analysis (that is, full haul, empty haul and loading processes).
\end{abstract}

\section{Keywords}

Potentially Acid-Forming (PAF) Rock, Non-Acid Forming (NAF) Rock, 
Truck Utilization, Truck Fill-Factor, Queuing Time, Loading Cycle Time, Full and Empty Haul, Total Cycle Time, Theoretical Cycle Time, Non-Productive Cycle Time, Cycle Time Performance Ratio

\section{Introduction}

Surface mining is the most common mining method worldwide, and open pit mining accounts for highest surface output. Open pit mining consists primarily of the removal of topsoil and overburden, drilling and blasting of ore, and the transportation of material using a system of excavators or excavators and haul trucks. The focus of this study was cycle time analysis including from loading of waste materials (carried out using excavators of different sizes located at several different locations) and transportation to different waste dumps within the open pit mine using trucks, a process carried out using an automatic dispatch system. Truck dispatching problem is one of assigning trucks to excavators in a well designed system on real-time basis so as to ensure the achievements of some goals or minimize the under-achievement of such goals. Ore reserves which exist near the surface are mostly depleted, leading to large amounts of waste rock requiring transportation.

The mining process studied generates two byproducts: waste rock (rock that is non-mineralized, or mineralized rock which contains insufficient gold to process economically) and tailings (the slurry that remains once the gold and silver have been extracted from the crushed ore at the processing plant). The focus of this study was on waste rock transportation, although other rocks are also generated at low rates. A special feature of the waste rock is that some of it contains sulphide and is capable of producing acid drainage when exposed to oxygen and water (referred to as potentially acid forming (PAF) rock). Waste rock without the potential to form acid drainage is referred to as non-acid forming (NAF) waste rock.

The trucks transport waste rock from open pits to the waste dump in cyclic nature. Considering the large number of truck dispatch per month, it is evident that a small reduction in a single cycle time would result in a significant increase in productivity. Thus, this paper will benefit open-pit mine operators since the waste rock transportation cycle time data is critically analyzed in order to highlight where corrective measures should be implemented.

In this study, external dumps were used to dump the waste rocks which are heterogeneous in terms of grain size and structure affecting the loading and dumping times for the trucks in a complex nature. This paper aims at assessing the performance of a truck-excavator system in open-pit mines and focuses on solid mine waste dumped directly with the truck without considering the dozer employed for pushing the materials. The significance of this study is based on the environmental impacts of mine waste, which requires the Waste PAF to be well managed. Because of high cost, mine operators tend to avoid proper man- 
agement of waste rock leading to environmental impacts especially when potentially acid forming (PAF) rocks are in large quantities.

This study is aimed also at assessing waste rock generation rate based on loading data by establishing daily waste material generation rate and average tonnage per dispatch for different waste categories. The truck utilization efficiency was also determined as a ratio of actual load to the maximum loading observed. This analysis is important due to huge and capital intensive equipment invested in open pit mine, life of which is very important from production and productivity point of view. Truck utilization problem was critically assessed in this study focusing on queuing delay, lower truck fill factor and hang time delays. The use of automatic dispatching system was effectively applied by the open pit mine for performance improvement advantages of which have been described in literature [1] [2] [3].

In an open-pit mine operation under review, a material handling system comprise of loading, hauling and dumping subsystems using a computerized dispatching system. Such a system is more productive than the non-dispatching mode. The system studied is over-trucked, i.e., many trucks per excavator (at a ratio of 3.5:1), leading to a need for dispatching, although the critical ratio trucks per excavator was not assessed. One of the most important factors affecting the required number of trucks is total cycle time. A cycle time is the time span which includes loading, transportation, dumping and maneuvering processes [4]. This study went deeper on analyzing cycle time data for seven components, using statistical analysis and Pareto principle. Development of effective and efficient material handling systems can only be developed through detailed analysis of these subsystems [5], such as the work reported in this paper. The effect of road characteristics was assessed via empty- and full-haul cycle time analysis [4]. Waste material transportation from production faces can also be accomplished using rail truck belt-conveyor or hydraulic transport.

\section{Literature Review}

\subsection{Material Transportation in Open Pit Mines}

In this study, cycle times for loading, transportation and dumping of waste rock or uneconomic mineralized rock was studied. The waste rock is normally removed to allow mining of the useful mineral resource. The amount of waste rock is however larger in open pit mine (compared to underground mine) and hence difference in operating costs. The waste rock includes granular broken rock and soils ranging in size from fine sand to large boulders, with fines content largely dependent on the nature of the formation and the methods employed during mining [6]. All these factors, in turn, affect the loading time and dumping time at the waste dump.

There are different types of mine waste materials which vary in their physical and chemical composition, their potential for environmental contamination, and how they are managed at mine sites. Generally, overburden has a low potential for environmental contamination, and is often used at mine sites for landscape 
contouring and revegetation during mine closure. On the other hand, waste rock is the material which contains minerals in concentrations considered too low to be profitably extracted. Waste rock is often stored in heaps or dumps on the mine site, but may be stored underwater with tailings if it contains a lot of sulphide minerals and has a high potential for acid rock drainage formation. Waste rock dumps are generally covered with soil and revegetated following mine closure, although there are cases of waste rock being re-mined in case of an increase in mineral market prices or improvements in extraction technology.

The waste rock loaded into trucks comprises of materials of different particle sizes and types which affect loading an dumping processes. The fragmentation of such rock is a product of a number of former mechanical processes, like drilling, blasting, ripping, etc. Thus, the waste rocks loaded, hauled and dumped may range in size at a waste dump from clay particles to boulders (e.g., less than 1.0 $\mathrm{mm}$ to larger than $1.0 \mathrm{~m}$ in diameter), which influence the loading and dumping times. Approaches for selection of haulage trucks, routes to dumps on the basis of minimizing the haulage cost is one of the main parameters in optimization studies conducted in the past [5] [7] [8], which is supported by availability of cycle time data.

\subsection{Cyclic Nature of Waste Rock Transportation System in an Open-Pit Mine}

The importance of analyzing production cycle in order to come up with the overall open pit mine performance was emphasized through targeting minimal production cycle times [9]. A number of works consider the impact of machine breakdown on production cycle time [10] [11], while others proposed an inventory model linked with production cycle optimization when materials flow into the production system [7]. This study focuses on material flow within a subsystem of an open pit mine including loading points and dumping points. While spares, fuel, oils flow into a subsystem forms an important factor, this study did not dwell on such inputs. By concentrating at each component of material transportation system, a detailed synthesis of performance problem was established. A production policy in which the length of the production cycle is kept between lower and upper limits has been explored [12], while other researchers determined the optimal cycle length of each product through minimizing the cost function [13].

Total cycle time is a crucial parameter from economic point of view for the calculation of number of trucks [4], and also throughput or production rate [14]. After loading, the haul trucks transport the waste rockout of the mine to a dumping location where the material will either be stored or further processed. The trucks then return into the mine and the cycle repeats itself. For most surface mines, truck haulage represents as much as $60 \%$ of their total operating cost [5], so that it is desirable to maintain an efficient haulage system. During aexcavator-truck mine operations, trucks cycle between their assigned excavators and dumps or crushers, through a network of haul roads. The total cycle times of the 
trucks are calculated as the sum of: load time, full-haul time, dump time, hang time, empty-haul time, queuing time at the excavator and spotting time before loading.

Where cycle times (or service times) are exponentially distributed, service rates are the inverse of mean service times [5]. Defining the back-cycle time as the truck cycle time minus the excavator waiting and loading times, leads to another important parameter in cycle time analysis, which require investigation. The mean service time depends on both excavator capacity and truck capacity. On the other hand, the mean back-cycle time depends on travel distance and truck speed.

Dumping of waste rock is a straight forward procedure during which very few operational parameters are believed to be significant. Larger buckets may require longer time to dump or the operator may speed up or retard the process. Based on literature, the dumping phase has been established to depend on bucket size, bucket fill factor and operator preference [15].

In this study, durations of seven steps of material transport operations were recorded extensively as sample points. The use of such sampling, together with analysis of the associated statistical distributions and equations, was assumed to provide an accurate and valid representation of the wider stochasticity of the processes in question. This technique of separating operational steps and performing detailed observations and analysis has already been extensively demonstrated in both the field of work sampling and broader statistical theory [13].

A framework for reducing material transportation cycle time is based on identifying the factors that affect cycle time components, and also establishing the actions that can be taken to diminish their impact [16]. Thus, bottleneck control in real time production [17] [18], prioritizing truck and excavator preventive maintenance [19], spare parts inventory for maintenance, optimization of initial buffer adjustment [20], reduction of machine setup time [21], and predicting order lead times [22], can lead to production improvement and cycle time reduction as trucks will come back to operations faster following breakdown, thus giving high truck availability [23] [24] [25] [26]. Moreover, the possibility of reducing cycle times in mass production by input and service rate smoothing has also been reported in literature [27].

\subsection{Cycle Time Performance Problem}

Cycle time is a direct measure of process and equipment performance in waste material transport for open-pit mines and other processes. Looking at different components of total cycle time, each step will come with a specific average cycle time to compare with other steps of the process. Once each step's cycle times are known, the bottlenecks are then determined as steps with longest cycle times. The ability to forecast the waste material transportation process is based on cycle time at the narrowest bottleneck. The optimal number of bottlenecks to focus on (due to limited resources) are then determined using Pareto principle [28] [29] [30]. It is important to assess bottlenecks in details based on cycle times of ma- 
terial transport components (to determine root causes) so as to prioritize continuous improvements or lean initiatives. Reduction in cycle time results in making the best improvements with fewer resources.

\section{Methodology}

\subsection{System Description}

Ore or waste is moved by 49 trucks from different excavator locations along a network of haulage roads, from 14 excavators located in 75 continuouslychanging locations of dumping or crusher stations. About 12 waste types were transported from excavators to different dumping areas. Through extensive time studies in the field, data was collected for loading cycle times, the truck travel times, waiting times for the trucks at the excavator and dump locations, and the truck dumping times. Statistical distributions were fitted using SPSS software for the observed data. These distributions permit the computer program to perform random selection and allocation of events for the defined sequence of operations, the so called dispatch system.

This study is based on field investigation conducted at GGM, an open-pit mine utilizing trucks of different capacities (DT Series), waste rock dumps located in different nearby places, different materials types transported, night and day shifts, excavators of different models and capacity (mainly the EX Series), etc. The dispatch data was available for the whole year, but this study focused on dispatches recorded in one month, during which the activities were assumed to be the same.

\subsection{The Data Collection Method and Assumptions}

In this study, a method of work sampling was implemented [17], for which cycle times to complete several steps of waste material transportation were recorded for a period of one month, for an open pit mine operating 24 hours per day, leading to $N=60,690$ data points. The aim of the work sampling method is to enhance capacity utilization in the production process. The data used in this study was generated and stored using an automated computer-based truck dispatching system. The purpose of such computer application is to improve the equipment utilization and increase production subject to a variety of practical constraints. The basic assumptions used include:

1) All trucks in the same model series are identical (their capacity, motor power, speed, etc., are the same).

2) All excavators in the same model series are identical (in terms of loading capabilities, similar probability distribution types and same parameters for loading process).

3) All material generated is loaded and transported on monthly basis, so that generation rate equals loading and dumping rates.

4) More than one truck can travel along different roads (i.e., trucks are allowed to overtake each other along the haul roads), such that one truck do not 
affect the travel tie of the other trucks.

5) All excavators and the dumping site can serve only one truck at a time and trucks may form queues at dumping points.

6) All trucks start operation at the parking area near the dumping point at the start of the shift and park there at the end of each shift.

7) Truck dispatch is random depending on the truck availability only.

\subsection{Data Coding}

The worksheet created in a database comprised of $N=60,690$ data points or rows consisting of columns of data of different data types (mainly string and numerical types) as per Table 1. Numerical data like time delays and tonnage hauled were not coded as they could be read directly into FORTRAN arrays. Table 1 shows the study area description of items used for data analysis while Table 2 summarizes the number of items coded and used in creating a computer code. In Table 2, different items were coded to create arrays of integers instead of strings data, to allow manipulations using FORTRAN program.

Table 1. Study area description.

\begin{tabular}{llc}
\hline \multicolumn{1}{c}{ Data items } & \multicolumn{1}{c}{ Data type } & Count \\
\hline Waste types & String of characters & 12 \\
Excavators & String of characters & 14 \\
Trucks & String of characters & 49 \\
Locations & String of characters & 75 \\
$\begin{array}{l}\text { Trucks-to-excavator ratio of } \\
\text { Maximum number of data points in one month, } N\end{array}$ & - & $3.5: 1$ \\
$\begin{array}{l}\text { Other data items (seven cycle time components, } \\
\text { tonnage of waste materials loaded and hauled) }\end{array}$ & - & 60,690 \\
$\begin{array}{l}\text { Excavator tonnage: } 6,7.5,27,30 \text { and } 33 \text { t } \\
\begin{array}{l}\text { Coded data items (trucks, excavators, locations } \\
\text { and material types) }\end{array}\end{array}$ & Numeric & 8 \\
\hline
\end{tabular}

Table 2. Sample of coded data from string to numeric type for implementation of FORTRAN program.

\begin{tabular}{ccccccccc}
\hline S/N & \multicolumn{2}{c}{ Truck } & \multicolumn{2}{c}{ Excavator } & Location & & & Material type \\
\hline 1 & DT101 & 8001 & EX102 & 1001 & CUT5 & 2001 & Hg Hard & 601 \\
2 & DT102 & 8002 & EX201 & 1002 & F1 & 2002 & HG Soft & 602 \\
3 & DT103 & 8003 & EX202 & 1003 & $\ldots$ & $\ldots$ & IG Hard & 603 \\
$\ldots$ & $\ldots$ & $\ldots$ & $\ldots$ & $\ldots$ & GHW2_1460\#01 & 2010 & $\ldots$ & $\ldots$ \\
$\ldots$ & $\ldots$ & $\ldots$ & $\ldots$ & $\ldots$ & GHW2_1460\#02 & 2011 & $\ldots$ & $\ldots$ \\
60688 & DT234 & 8019 & EX307 & 1012 & $\ldots$ & $\ldots$ & Top soil & 610 \\
60689 & DT202 & 8010 & EX202 & 1013 & NY5_1250\#01 & 2074 & Waste NAF & 611 \\
\hline
\end{tabular}




\subsection{Determination of Quantities of Waste Rock Generation Rate}

The monthly dispatch frequencies for each material type, with the tonnage loaded was used to determine the total frequencies for each material by crosstabulation. Knowing the tonnage for each dispatch $\left(L_{i}\right)$ and frequency for each material type $\left(n_{i}\right)$, the total tonnage for each material $\left(W_{i}\right)$ was determined as peer Equation (1):

$$
W_{i}=\sum_{k=1}^{4} n_{i} \times L_{i}
$$

\subsection{Determination of Average Truck-Fill Factor}

Given the truck tonnage values, $L_{i}=6,7.5,27,30$ and 33 tons, with the maximum tonnage, $L_{\max }=33$ tons of waste materials, the truck fill factor, $f_{i}$, was defined as per Equation (2):

$$
f_{i}=\frac{L_{i}}{L_{\max }}
$$

The average truck fill factor for trucks using loading data is given for $N=$ 60,690, as per Equation (3):

$$
\bar{f}=\frac{1}{N} \sum_{i=1}^{N} \frac{L_{i}}{L_{\max }}
$$

\subsection{Cycle Time Analysis}

Cycle time analysis was conducted starting with identification of the activities to be analyzed, for which the cycle times of seven activities were determined and recorded. The total cycle time for the truck (also called the actual time) was determined as per Equation (4):

$$
T_{c t}=\left[t_{q}+t_{s p}+t_{L d}+t_{f h}+t_{d p}+t_{h g}+t_{e h}\right]
$$

where $t_{q}=$ queuing time at the excavator, $t_{s p}=$ spotting time, $t_{L d}=$ loading time, $t_{f h}=$ full haul time, $t_{d p}=$ dumping time, $t_{h g}=$ hanging time and $t_{e h}=$ empty haul time. During dispatching, all the seven time delays were recorded automatically and saved as numeric data together with other details (string type data) shown in Table 2, also for $N=60,690$ data points. Using the total cycle time and a known tonnage of waste material transported, the production capacity, $P_{c p}$, (which is a measure of throughput) for the waste rock transportation system was estimated as per Equation (5):

$$
P_{c p}=\left(\frac{L_{i}}{T_{c t, i}}\right)
$$

The theoretical time (total time for value added activities or processes during which material is attached to the machines) was determined using Equation (6):

$$
T_{t h}=\left[t_{L d}+t_{f h}+t_{d p}\right]
$$

The cycle time for non-productive time, $T_{n p}=$ was determined as per Equation (7): 


$$
T_{n p}=\left[t_{h g}+t_{s p}+t_{h g}+t_{e h}\right]
$$

Thus, the productive fraction of the cycle time was calculated based on Equations (4) and (7) as per Equation (8):

$$
f_{p}=\left(1-\frac{T_{n p}}{T_{c t}}\right)
$$

On the other hand, the cycle time performance ratio $\left(T_{P R}\right)$ was determined using Equation (9):

$$
T_{p r}=\left(\frac{T_{c t}}{T_{t h}}\right)
$$

In practice, $T_{p r}>1.0$ since $T_{t h}$ is shorter than $T_{c t}$. The objective of cycle time analysis is thus to determine corrective actions to drive $T_{p r}$ and $f_{p}$ towards a value of 1.0, by reducing or eliminating non-productive activities during engineering design and also during mine operation.

\subsection{Normalization of Cycle Time Data}

Due to differences in the magnitudes of cycle time components, the values of cycle times were normalized to yield values between 0 and 1, to allow for comparison, that is, $X_{n m, k}$ using Equation (10):

$$
X_{n m, k}=\left(\frac{X_{k}-X_{\min }}{X_{\max }-X_{\text {min }}}\right)
$$

where $X_{k}=k^{\text {th }}$ value in the original cycle time data, and $X_{\min , k}$ and $X_{\max , k}=$ minimum and maximum values in the time series being analyzed, respectively. The normalized values were then determined for selected cycle time components.

\section{Results and Discussion}

\subsection{Waste Rock Generation, Loading Rate and Stripping Ratio}

The waste material generated during the study period constituted the largest volume of materials generated from the open pit mine per day, relative to the ore extracted. It was observed (based on Equation (7)) that the waste generation rate was about 38,722 and $5740 \mathrm{t} \mathrm{NAF}$ and PAF waste rocks per day, respectively, out of the total waste generation rate of 55,772 $\mathrm{t} / \mathrm{day}$, as summarized in Table 3. Taking NAF and PAF as the main waste rock components, the dilution factor was estimated to be $80 \%$.

Figure 1 presents the monthly average tonnage for different types of materials generated an hauled from the open-pit mine. The waste rock fraction based on loading data was estimated to be about $81 \%$ the rest being other waste materials or estimated total material to waste ratio of $1.25: 1$, which agrees well with literature data for most mineral types [6]. Comparing the amounts of Waste NAF and Waste PAF and other materials transported in the three-month period (August-October), that is, 3.356, 0.892 and 1.011 million tons, respectively, the fraction of waste material or dilution factor was estimated to be $79.3 \%$, or a ratio of 
Table 3. Determination of material generation rate from monthly truck loading dispatch data.

\begin{tabular}{|c|c|c|c|c|c|c|c|c|c|}
\hline Tonnage & $6 \mathrm{t}$ & $7.5 \mathrm{t}$ & $27 \mathrm{t}$ & $30 \mathrm{t}$ & $33 \mathrm{t}$ & Total dispatches & $\mathrm{t} / \mathrm{month}$ & t/day & Tons per dispatch, $T_{p d}$ \\
\hline Waste NAF & 0 & 0 & 716 & 3571 & 32543 & 36830 & $1,200,381$ & 38,722 & 32.6 \\
\hline Waste PAF & 0 & 0 & 244 & 5712 & 0 & 5956 & 177,948 & 5,740 & 29.9 \\
\hline HG Hard & 2729 & 3284 & 936 & 1340 & 8 & 8297 & 131,408 & 4,239 & 15.8 \\
\hline MG Soft & 468 & 1053 & 0 & 697 & 3024 & 5242 & 106,740 & 3,443 & 20.4 \\
\hline HG Soft & 61 & 93 & 0 & 698 & 435 & 1287 & 36,359 & 1,173 & 28.3 \\
\hline MG Medium & 557 & 165 & 0 & 154 & 0 & 876 & 22,473 & 725 & 25.7 \\
\hline IG Soft & 0 & 0 & 0 & 0 & 681 & 681 & 14,817 & 478 & 21.8 \\
\hline IG Hard & 0 & 0 & 541 & 0 & 0 & 541 & 14,607 & 471 & 27.0 \\
\hline MG Hard & 0 & 0 & 282 & 193 & 1 & 476 & 13,437 & 433 & 28.2 \\
\hline LG Soft & 0 & 0 & 0 & 0 & 449 & 449 & 9,200 & 297 & 20.5 \\
\hline LG Medium & 0 & 4 & 0 & 39 & 0 & 43 & 1,200 & 39 & 27.9 \\
\hline Topsoil & 0 & 0 & 0 & 12 & 0 & 12 & 360 & 12 & 30.0 \\
\hline Total & 3815 & 4599 & 2719 & 12416 & 37141 & 60,690 & $1,728,929$ & 55,772 & - \\
\hline
\end{tabular}

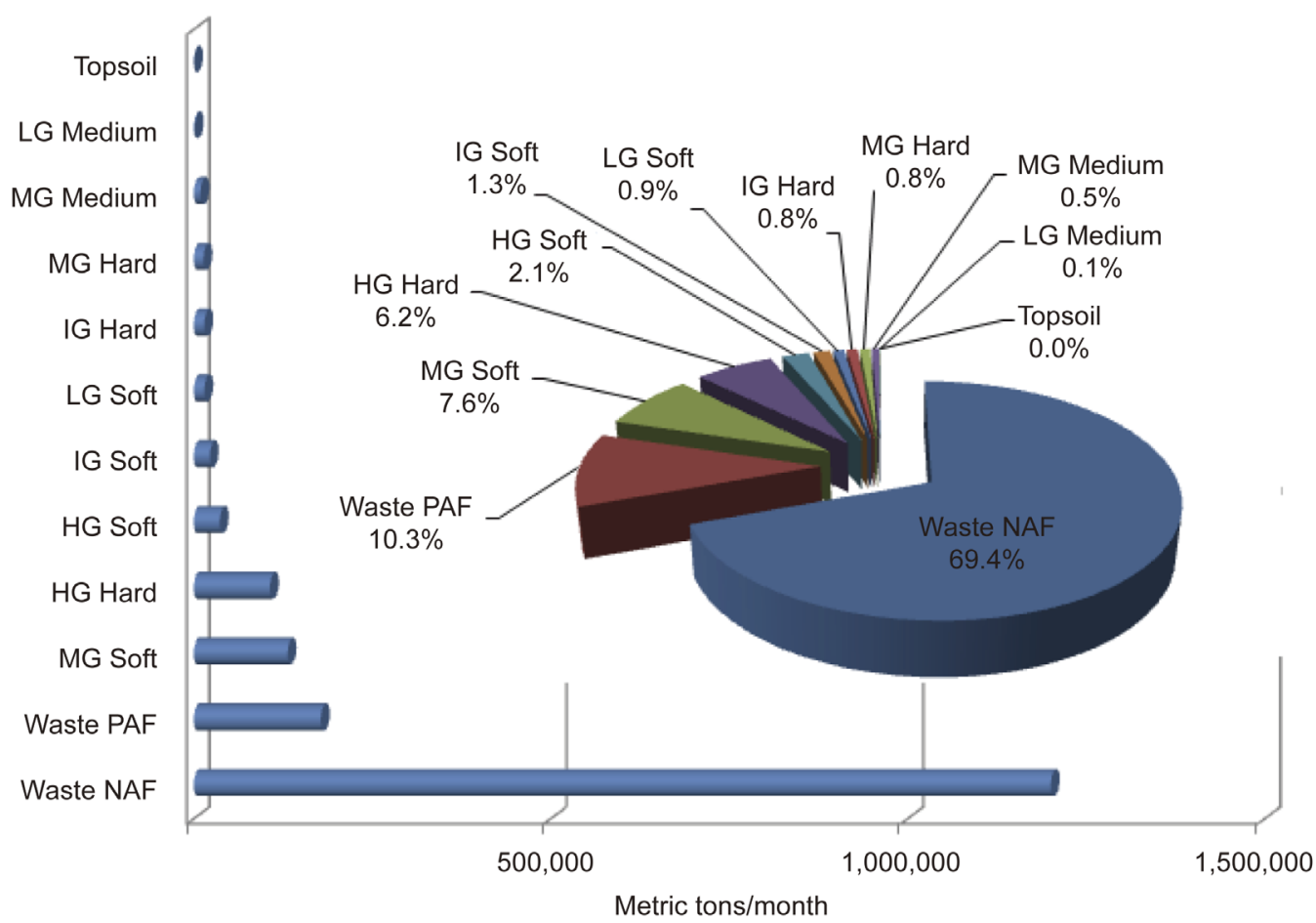

Figure 1. Distribution of material generated and hauled from an open-pit per month.

waste rock to other material of 3.83:1. As mine operations continue, this factor is supposed to decrease as higher grades ores are reached. The ratio of waste-rock to ore (i.e., the stripping ratio) at surface mines may range as high as 10:1 for some areas with typical value ringing from 1:1 to 3:1 for most mineral types [12], which agrees well with study results. Areas with high stripping ratio will lead to high dumping rate at waste piles, and vice versa. 
Figure 1 shows also the distribution of materials loaded and hauled from the open-pit mine per month for the period of four months, presented using both bar chart (in metric tons per month) and pie-chart. The four types of materials loaded at largest amounts include Waste NAF (69.4\%), Waste PAF (10.3\%), MG Soft (7.6\%) and HG Hard (6.2\%). The waste materials, however, comprised of the largest part all the time (on daily and monthly basis).Examining the distribution of tonnage of materials loaded and hauled it is evident that waste materials transportation takes the major part of the total cost of mine operations.

\subsection{Truck Fill-Factor as Utilization Efficiency in the Open-Pit Mine}

By cross-tabulating the tonnage hauled per trip versus the truck codes from Table 2 from monthly dispatch data, it was established that all trucks could carry $33 \mathrm{t}$ per trip as a maximum load observed in this study based on dispatch logs. This data could also be obtained from manufacturers' datasheets. It was further observed that the percent of dispatch frequency during which the trucks were loaded at $33 \mathrm{t}$ of the materials from the open pit mine was higher than $0 \%$ for all trucks, which indicates that all trucks could carry 33 t. However, dispatch frequencies with trucks loaded below $33 \mathrm{t}$ were as high as $89 \%$, signifying under-utilization of the trucks. Figure 2 shows the fraction of trips for which the trucks were under loaded $(f<100 \%)$. While some trucks were highly under-loaded $(f<10 \%)$ for most of the trips, only 9 trucks (or $18.4 \%$ ) were loaded from $70 \%$ to $90 \%$. Figure 2 shows also that all trucks were under-loaded from time to time, with large number of them (22 trucks or $43 \%$ ) being severely under-loaded $(f<10 \%)$.

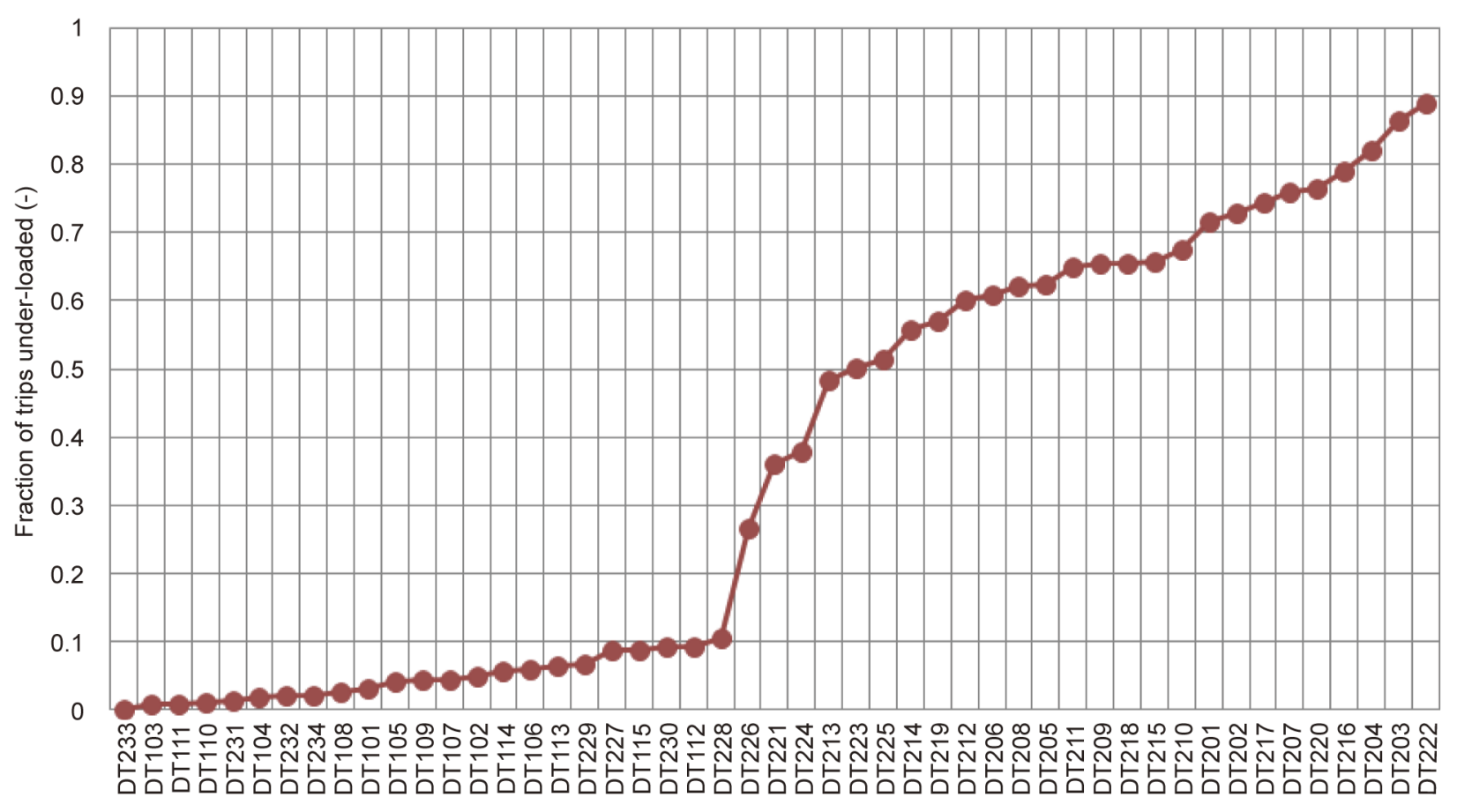

Figure 2. Variation of truck trips under-loaded in a material transportation system. 
Figure 3 shows the variation of the dispatch frequency with tonnage of materials transported by each truck during one month. A linear relationship shows that the higher the dispatch frequency, the higher the tonnage of materials transported, as expected. However, the linear regression line with $R^{2}=0.9942$ $(<1.0)$ indicates that there are cases of dispatch where the trucks are loaded at lower fill-factor, which complements the results presented in Figure 2. The slope of 34.2, higher than 33.0 indicates that there were large number of cases where the fill-factor was higher. Thus, the truck-excavator system was being underutilized by loading the trucks below their respective pay load.

The dispatch-tonnage relationship was established based on data from different locations (meant to assess the effect of locations on truck utilization), different materials loaded and loading data for different trucks. Such relationship led to a performance parameter denoted astons loaded per dispatch, $T_{p d}$. Results show that $T_{p d}$ values differ according to the three scenarios, such that, material-, truck- and location-based values, were observed to be 20.05, 28.90 and 29.97, respectively. The lower value of material-based $T_{p d}$ shows that there is tendency to underload the trucks when specific materials are being loaded. This is also revealed by data presented in Table 3, from which $T_{p d}$ values for HG Hard, MG-Soft, LG Soft and IG Soft were lowest compared to other materials, that is, $15.8,20.4,20.5$ and $21.8 \mathrm{t} /$ dispatch, respectively.

The truck fill-factor is a key performance indicator(KPI) for material transportation system. Other researchers regard fill factor as a quality loss. To establish the maximum load, the truck identification codes were cross-tabulated with

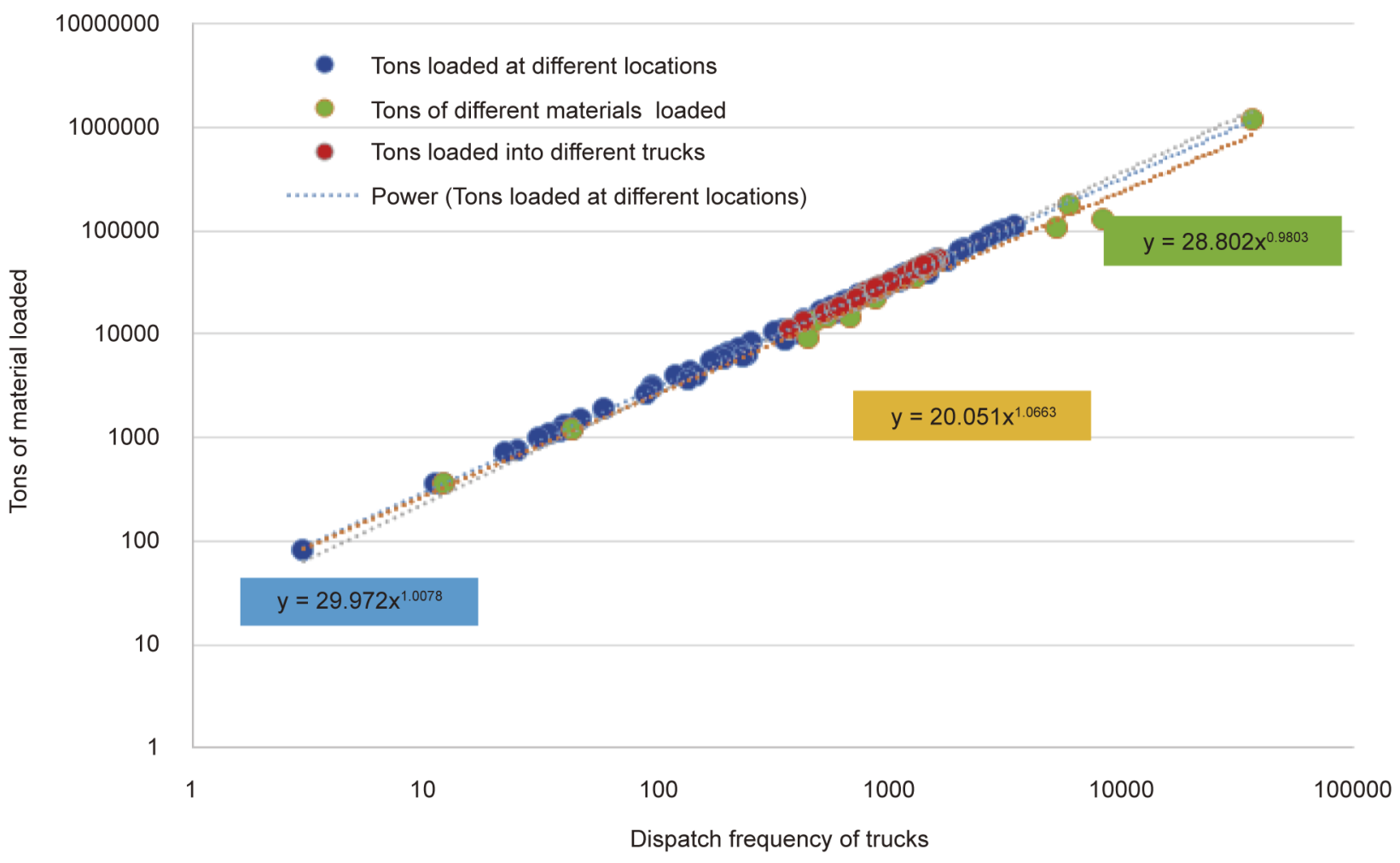

Figure 3. Variation of dispatch frequency with tonnage of materials transported by respective trucks during one month. 
the tonnage carried. Given the tonnage loaded at five fixed values $(6,7.5,27,30$ and $33 \mathrm{t}$ ), the values of fill-factor established were also fixed at $18.18 \%, 22.73 \%$, $81.8 \%, 90.91 \%$ and $100 \%$, respectively. Figure 4 shows the frequency distribution of fill factor levels for dispatch data recorded in one month. In general, higher fill-factors of $100 \%$ and $90.91 \%$ were observed at higher frequencies of $61.2 \%$ and $20.5 \%$, respectively, during which Waste NAF and Waste PAF materials were being transported. This indicates a good performance for waste material transportation. Statistical analysis of fill-factors revealed a mean value of $\bar{f}=86.33 \%$ with a standard deviation of $26.8 \%$. The values of fill-factors for different material types loaded are presented in Figure 4, which ranged from 1.0 to 0.3 , being minimum for IG Medium and maximum for IG-Soft.

The bucket efficiency ratio, a measure of what weight of waste material a bucket of particular excavator capacity can carry, is rated in $\mathrm{t} / \mathrm{m}^{3}$ and ranges from $2.0 \mathrm{t} / \mathrm{m}^{3}$ for backhoe to $2.16 \mathrm{t} / \mathrm{m}^{3}$ for rope excavators, based on which, the fill factor is generated during loading. However, the buckets are either under-filled
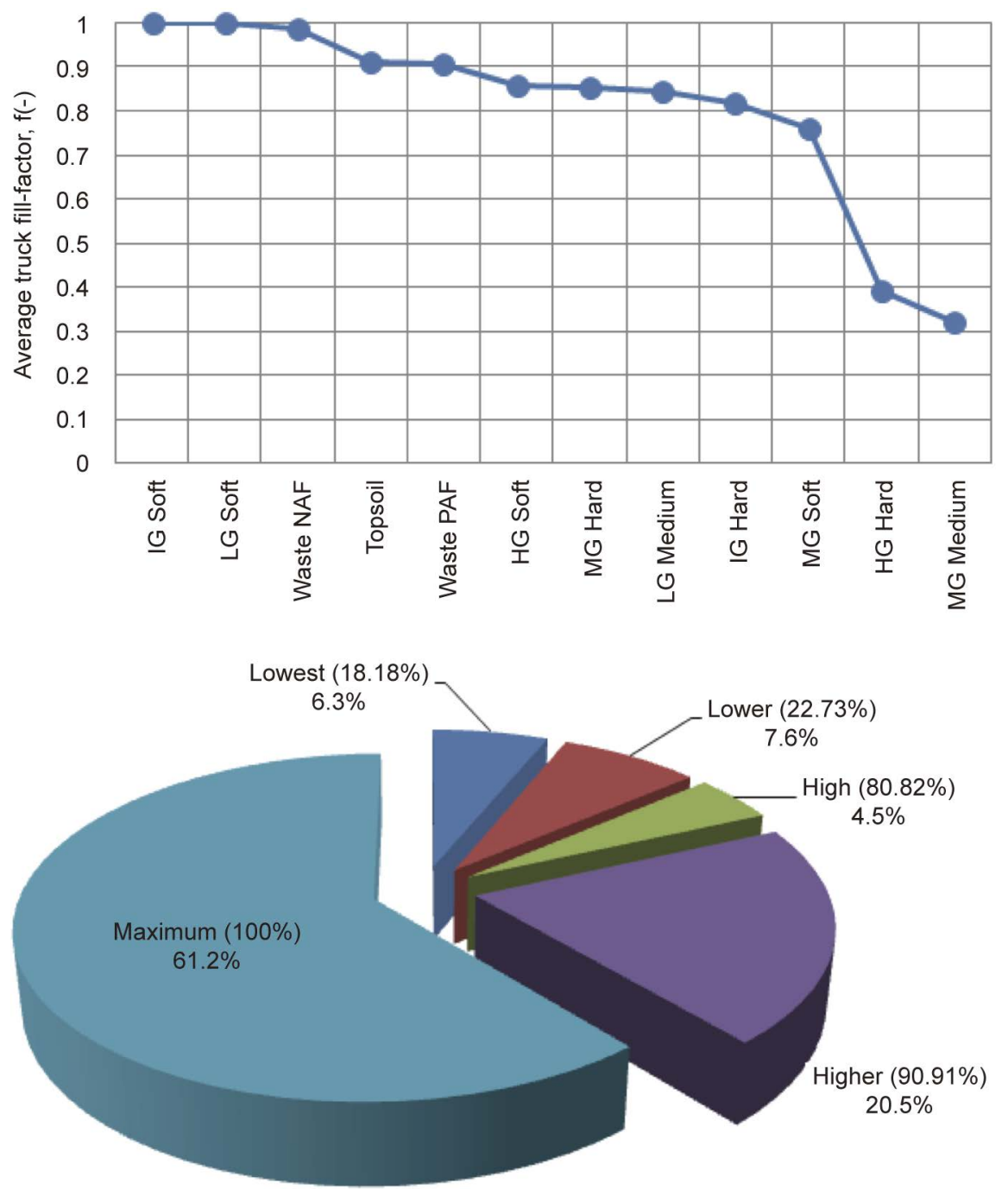

Figure 4. Distribution of truck fill factors for different material types loaded (bar chart) and overall distribution based on dispatch frequency data (pie chart). 
or overfilled similar to trucks with fill factors from 0.4 to 1.2 in practice [31], which in turn affects loading cyce time and lowers the tons per day presented in Figure 3.

\subsection{Queuing Time as a Truck Utilization Challenge}

In open-pit mining operations, material haulage trucks form queues on arrival at excavators, crushers, and dump locations and have to wait their turn in line [13] [32]. This study focuses on queues formed at the excavator prior to loading. When representing loading operations with queuing systems, the time a truck spends positioning and spotting at the excavator can be included either as part of the loading cycle time or as part of the time the truck was waiting in the queue for service. In this study, the latter queueing time was assessed. The data comprised of two parts, one with no queuing time at all during which the trucks were loaded after completing the empty haul (40.5\% of the time) and another part with varying queuing time (59.5\% of the time).

The average queuing time was observed to be 124.1 seconds, showing that the time wasted for queuing is high when compared to loading time. Figure 5 shows the PDF of queuing time data for 32,543 data points with average values observed for queueing time caused by different excavators. While strong variations in the queuing time leads to wide span of values on a PDF from 1 to 1000 seconds, the average values observed for all excavators fall within a narrow span (between 102 and 201.1 seconds only as shown inside Figure 5.

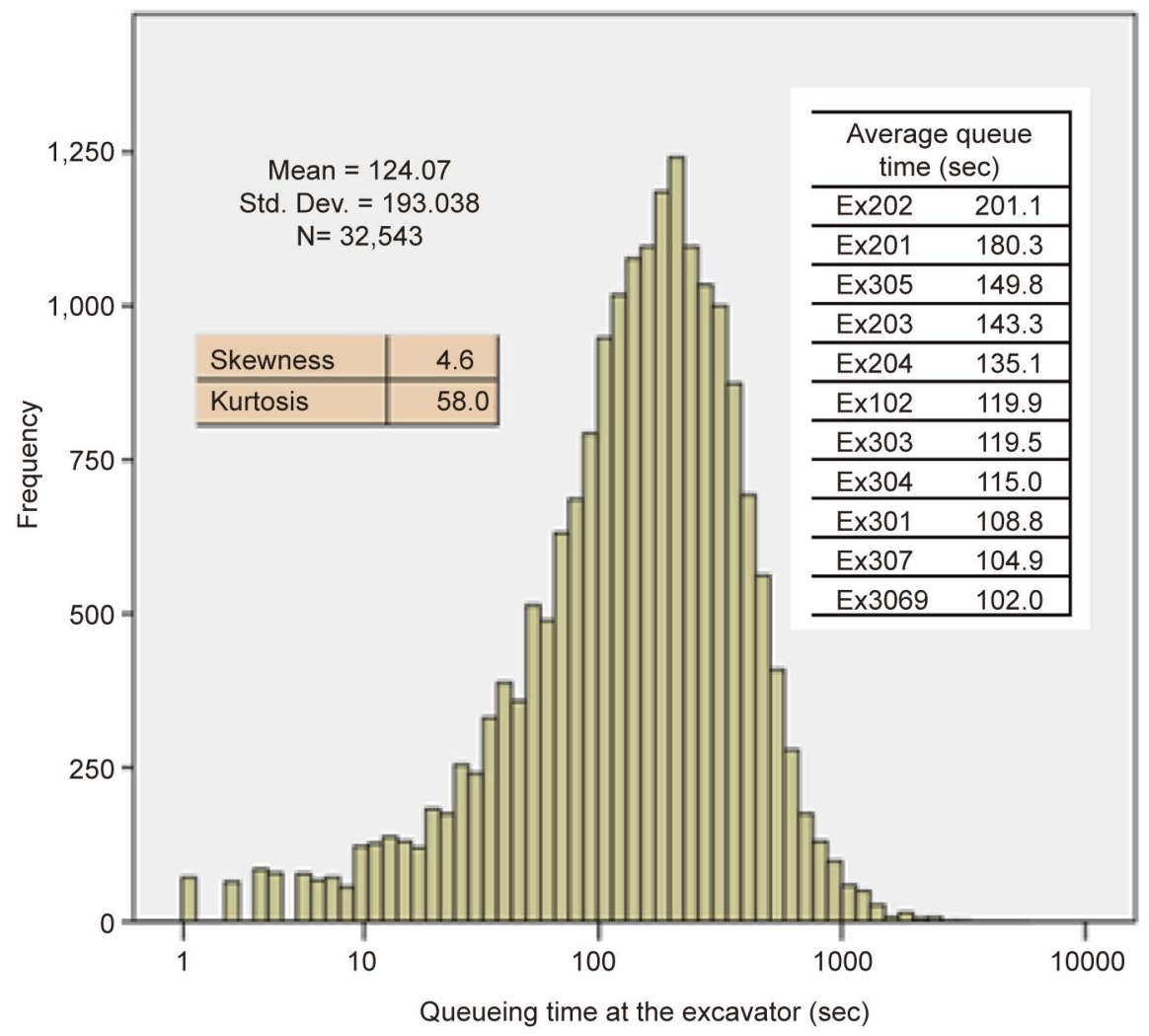

Figure 5. Histogram of queuing time data before loading $33 \mathrm{t}$ of Waste NAF. 
The amount of time trucks spend waiting to be loaded, $t_{q}$, is an indicator of how efficient the truck-excavator system is operating. The larger the values of $t_{q}$ the longer trucks are spending idling at the excavators. It should be noted that an idling equipment due to queuing is still not available and also not utilized during that time [24], even when the trucks are fit for work [23] [25] [26]. Cycle time reduction for queuing process is critical. To reduce queuing time, operators need to ensure that they are in the correct waiting position prior to reversing for being loaded.

\subsection{Analysis of Truck Loading Cycle Times}

Figure 6 gives a comparison of statistical analysis results for loading cycle times of waste materials (NAF and PAF) for fixed tonnage loaded (30 and 33 tons). Despite the differences in frequency, the PDFs have the same shape for all loading operations. For the waste NAF, the average loading time decreased slightly from 141 to 134.6 seconds when 33 and 30 tons were loaded, respectively. For the same tonnage of $30 \mathrm{t}$, the average loading time was slightly higher for Waste PAF $\left(L_{t}=137.4\right.$ seconds $)$ than for the Waste NAF $\left(L_{t}=134.6 \mathrm{sec}\right)$. The histograms reveal low positive skewness of 1.242, 1.627 and 1.416 for waste PAF (30 t), waste NAF (33 t) and waste NAF (30 t), respectively, and kurtosis values equal to 5.09, 7.60 and 6.30, respectively. All loading cycle time data are positively skewed, indicating presence of cases with very high values of $L_{t}$ at low frequency. Different from queuing time data, which leads to logarithmic PDF, the loading data leads to linear PDF.

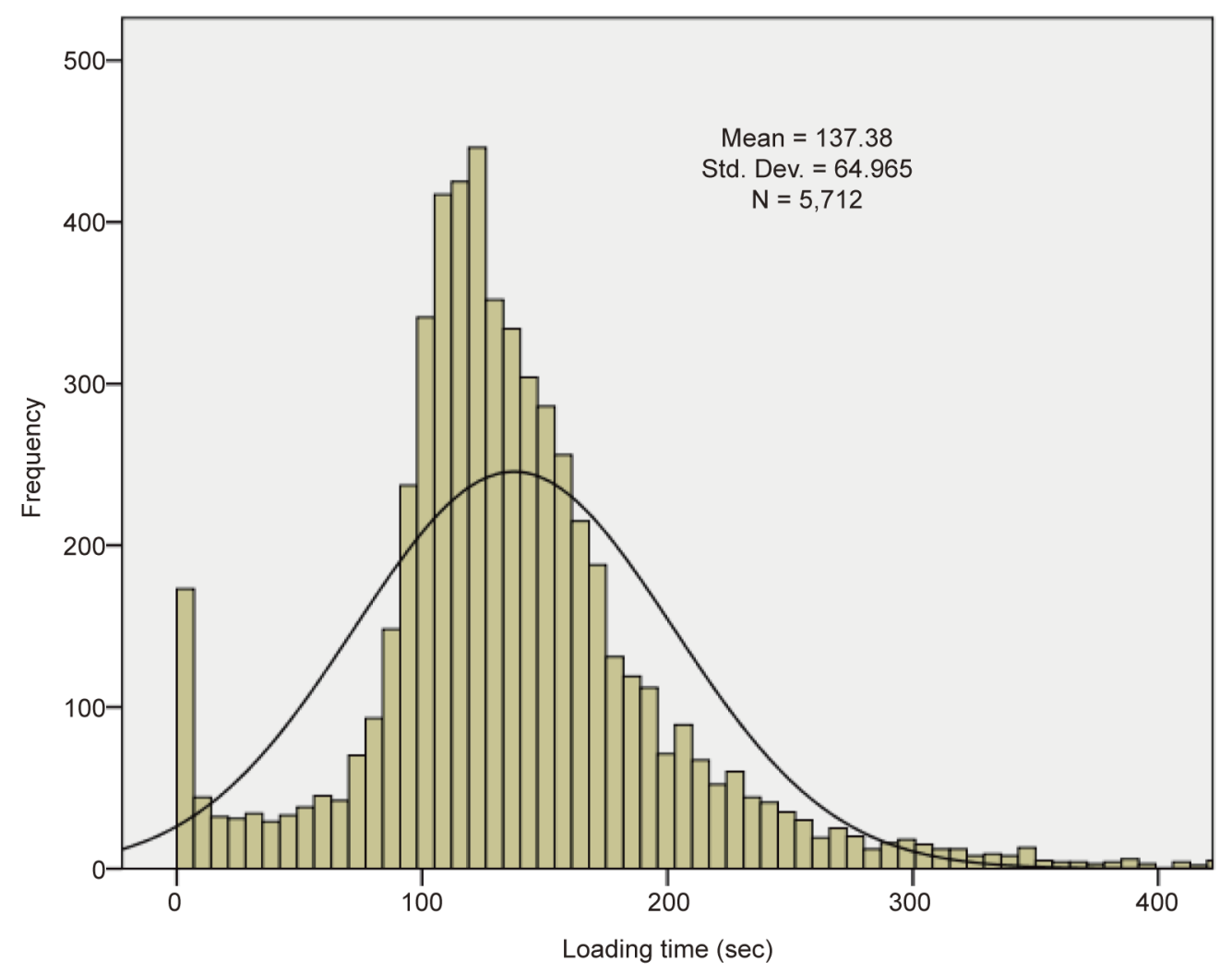



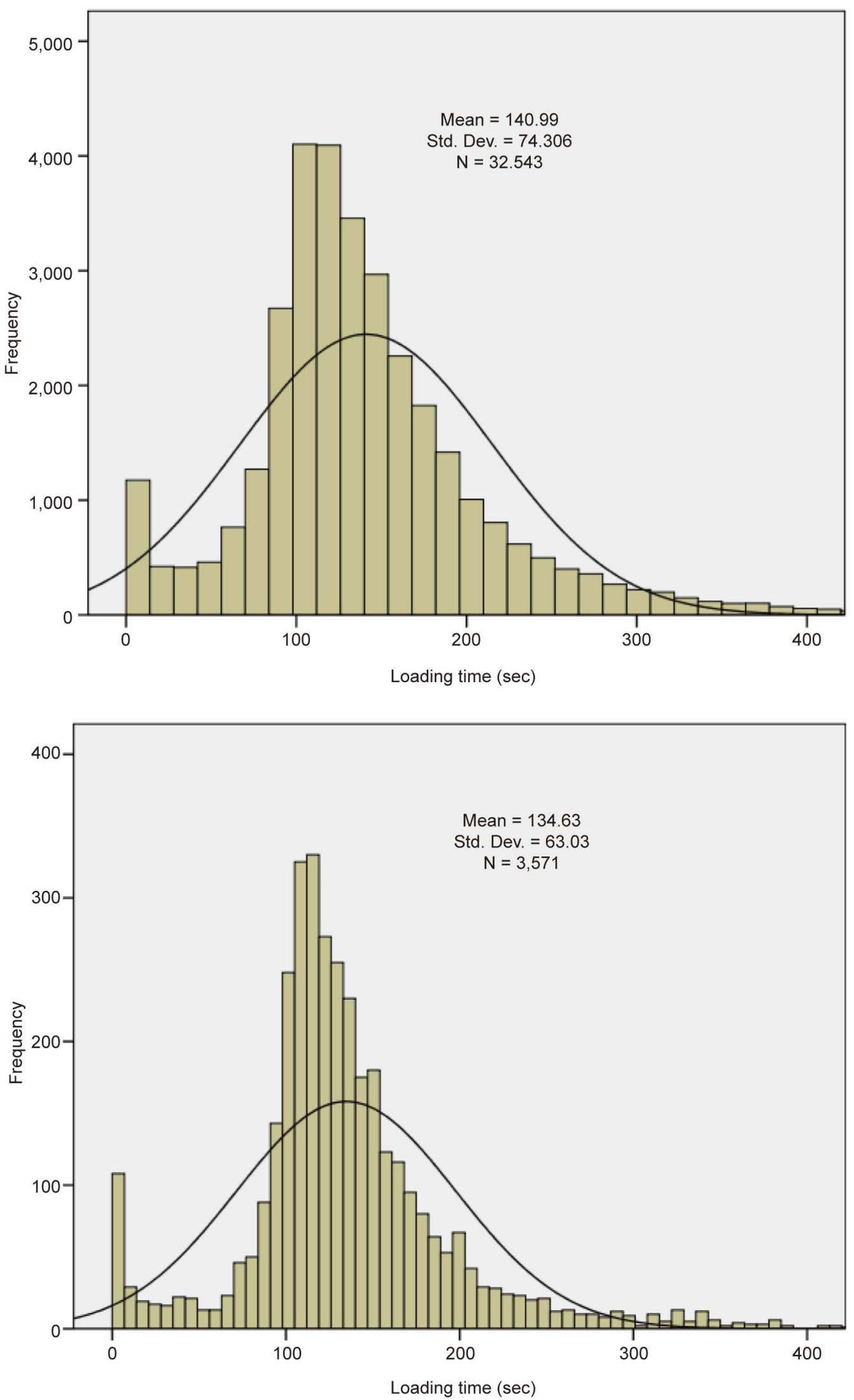

Figure 6. Histograms of the loading cycle time for waste materials in an open-pit mine(for PAF $30 \mathrm{t}$, NAF 33 and NAF $30 \mathrm{t}$ ). 
The horizontal axis in Figure 6 shows that loading time spans beyond 400 seconds in all cases, indicating that excavators do not take exactly the same time to load the same trucks even when loading the same quantity of waste materials. The stochastic nature of the loading process is affected by type and particle size distribution of material, which change from time to time even in the same location, while factors like excavator and truck pan design are constant. Higher values of $L_{t}$ can result from larger particle size of loaded material which in turn affect bucket fill factor. Since the rocks may range in size from less than $1 \mathrm{~mm}$ to larger than $1 \mathrm{~m}$, the loading time will vary accordingly.

Loading times depend on excavator capacity, digging conditions and the truck bucket design and capacity. Queues often form at the excavators since many tracks of various sizes are used at individual excavators, making allocation of trucks to the excavators and pits to become a complex engineering problem. The stochasticity of loading times, portrayed in Figure 6 can also be attributed to the difference in loading techniques associated with each type of loading unit, location design, orientation of trucks versus the excavator, and loading area cleanliness and elevation. The loading techniques depend on whether an hydraulic excavator, hydraulic/electric excavator, rope-shovel, front-end loader, etc., is used. Together with damage to the trucks, overloading the trucks leads to extended loading time.

\subsection{Analysis of Dumping Cycle Times}

Figure 7 presents the histograms of the waste material dumping times for trucks

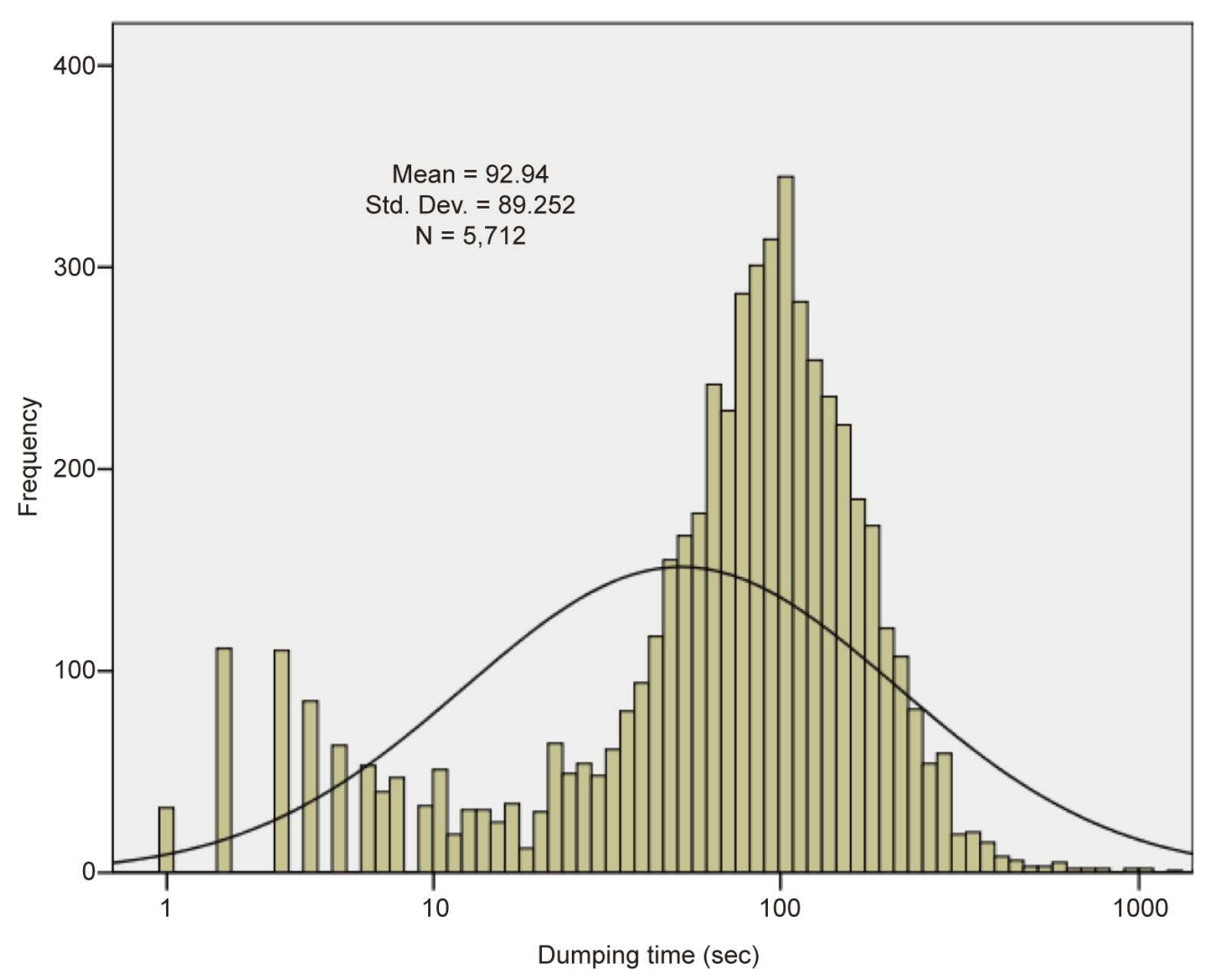



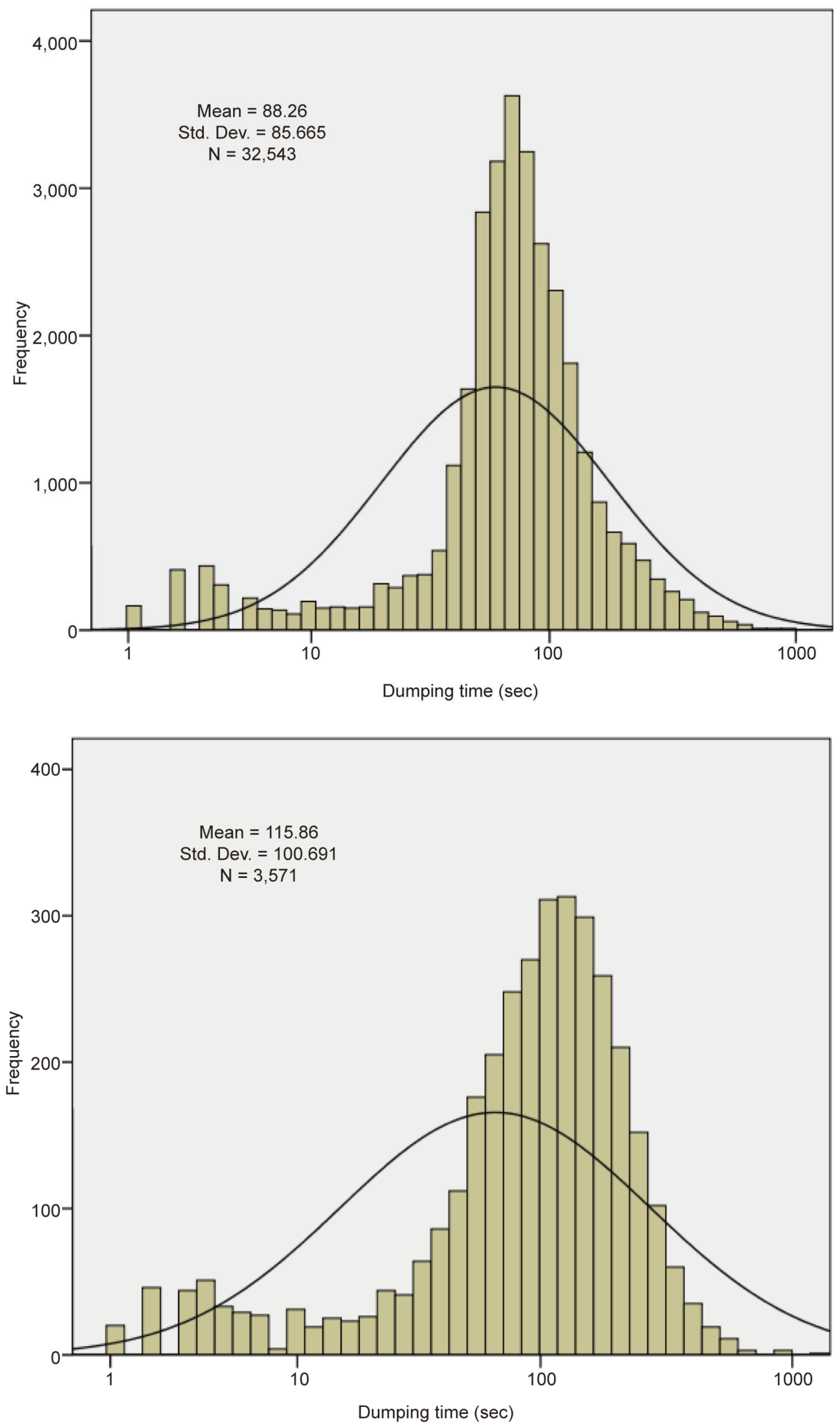

Figure 7. Histograms of the dumping cycle times for waste materials in an open-pit mine (for PAF $30 \mathrm{t}$, NAF $33 \mathrm{t}$ and NAF $30 \mathrm{t}$ ). 
at the waste dumps. When $30 \mathrm{t}$ of waste were loaded, the average dumping time changed from 93 to 116 seconds for Waste PAF and NAF, respectively. For the same waste material, NAF, loaded at 33 and $30 \mathrm{t}$, the dumping time increased from 88.3 to 116 seconds, respectively, which is rather too long and whih is opposite to the expected trend when tonnage is increased. This can be attributed to several reasons, including dumpsite design, truck load maneuvering prior to dumping, etc. The PDFs differ in shape from those of loading indicating that different factors affect the stochastic nature of the dumping compared to the loading process. Moreover, compared to the loading data, the PDFs for dumping process shows a clear shift from normal PDF curve (shifted to the right) while the peaks of the PDFs for loading cycle time data coincide with those of normal distribution. On the other hand, dumping times are shorter than loading times, as expected. Longer dumping cycle time can be attributed to poor level of dump area in all directions which leads to unstable dumping platform, and longer times for trucks to position before dumping. Moreover, dumping uphill takes longer as greater energy is required to lift the load.

Weather conditions affect the moisture content and hence shear strength of the waste rock which in turn affects the dumping and loading time depending on soil or material type and particle size distribution. Other factors affecting dumping time include dumpsite shape configuration such as valley-fill, crossvalley, side-hill, ridge, or heaped, depending on the topography of the dumping area, leading to increased stochasticity of the dumping process. The dumping method will also affect the dumping time depending on whether it is enddumping, push-dumping, free-dumping or plug-dumping.

\subsection{Waste Material Full and Empty Haul Cycle Times}

Figure 8 shows the PDFs for full-haul times for trucks loaded with fixed tonnage $(33 \mathrm{t}$ ) of waste NAF and also for the empty-haul data (which have no correlation to tonnage loaded or dumped). Both PDFs are logarithmic in nature, and depend on truck characteristics and driver behavior. Considering all trucks loaded with fixed material type at the same tonnage (Waste PAF, $30 \mathrm{t}$ ), the average fullhaul cycle time was observed to be 892.7 seconds, while the average empty-haul cycle time was 682.8 seconds. The empty-haul cycle time data was analyzed after dumping, so that the results are not related to the tonnage and material type hauled before dumping.

Results indicate that the full-haul process takes longer time than empty-haul, which is obvious for loaded and unloaded trucks, using same roads. The shapes of the histograms show a marked difference in the tails on both sides, with $S_{k}=$ 0.56 and 5.39 for full-haul and empty-haul cycle times, respectively. The empty-haul cycle time data shows wider variations away from the mean values than full-haul based on wide differences in skewness and standard deviation values ( $\sigma_{f h}=271.6$ and $\sigma_{e h}=561.3$ ). Thus, stringent control of drivers' behavior after dumping waste materials should be imposed to improve waste material transportation efficiency. 
Figure 9 shows the cumulative functions of the normalized full- and empty-haul cycle time data for different trucks. Comparing the normalized full-haul cycle time data for the four selected trucks, it is evident that there is a marked difference in terms of median values, for instance, reached at increasing cycle time in the order of DT103, DT101, DT102 and DT104. The cumulative function gives a measure for differentiating performance between different trucks, which could not be easily deduced from the PDFs. On the other hand, the empty haul times show similar order of performance using median values. The fact that the empty-haul is shorter than the full-haul time is portrayed by short time to reach median (50\%) for the former than the latter times.

Hauling waste material from the excavator production faces to the dumping sites is accomplished through a network of haul roads which is extremely complex, covering large surface areas and passing through extreme elevation changes. Other studies show that haul road grade affects strongly the truck speed [14], and hence the full- and empty-haul time. Other adverse conditions affecting
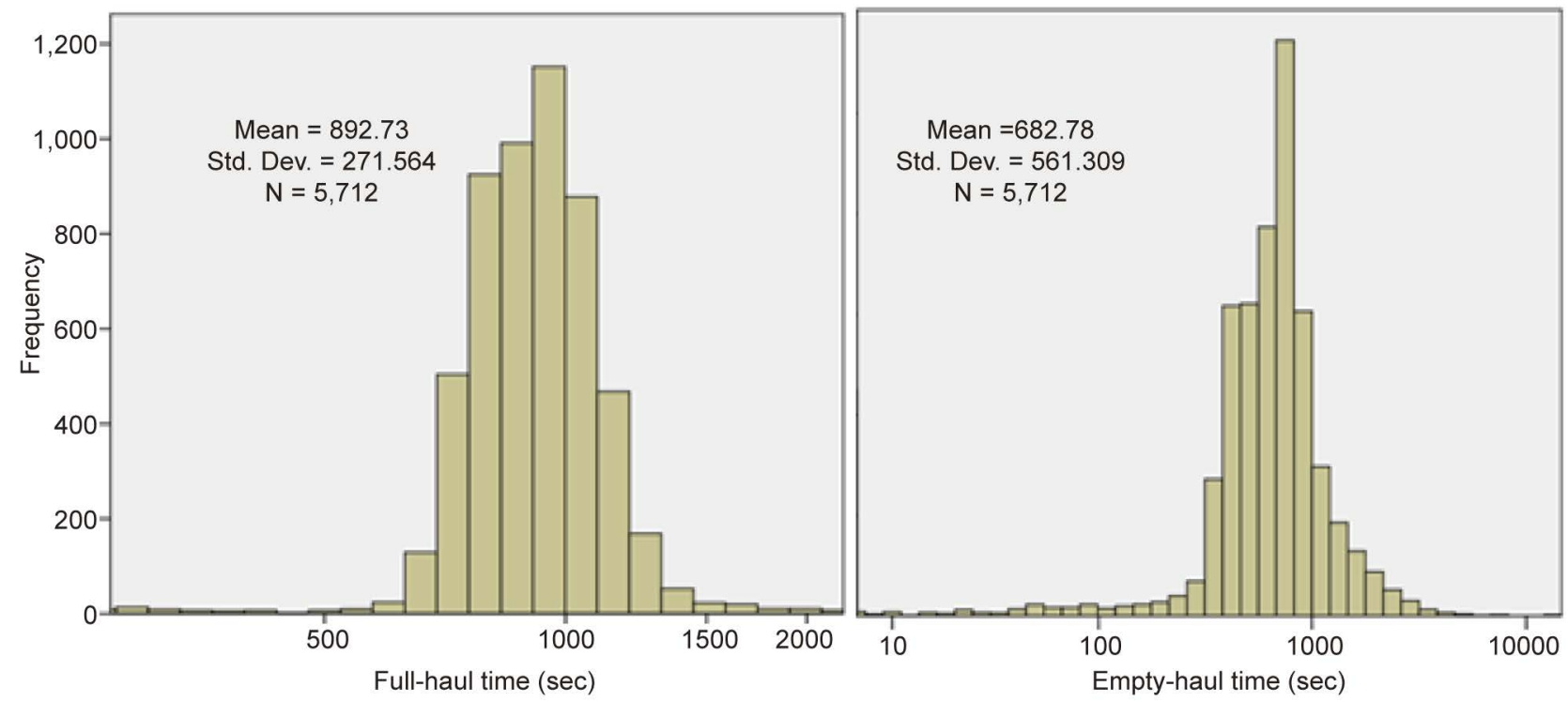

Figure 8. Histograms of full- and empty-haul cycle time data for waste material transportation (Waste NAF at $30 \mathrm{t}$ ).
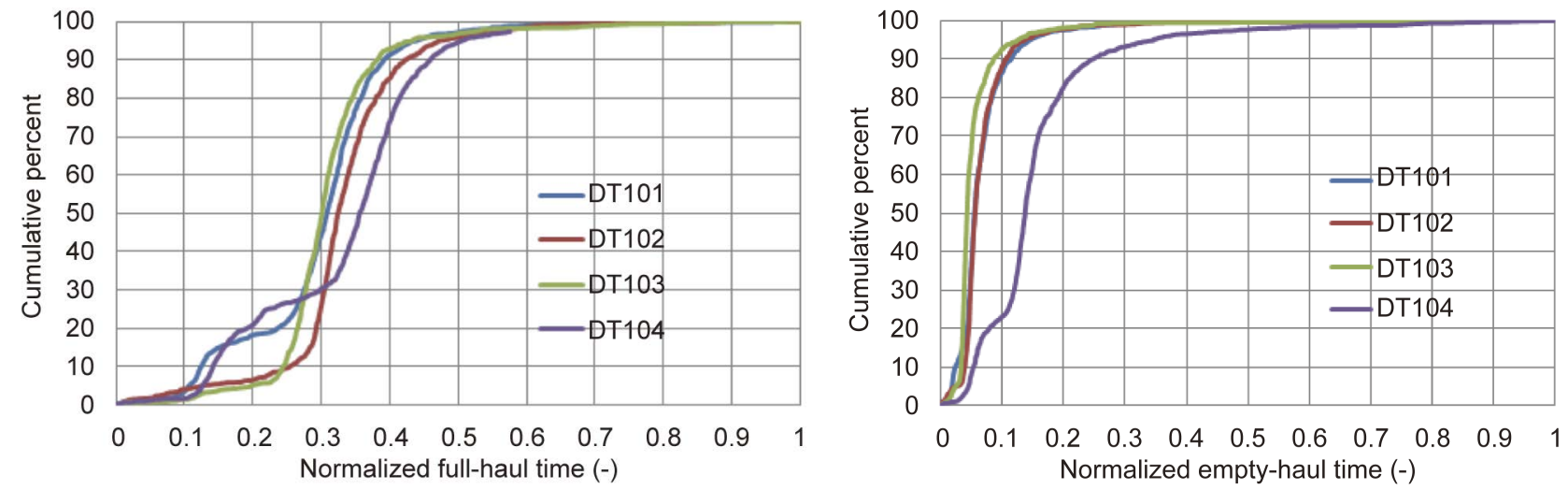

Figure 9. Cumulative functions of normalized cycle times for full- and empty-haul data for different trucks hauling $30 \mathrm{t}$ of Waste NAF. 
hauling times include dust, slippery wet surface and poor visibility. There are times and circumstances when adverse driving conditions require drivers to take extra care, leading to extended haul times, since vehicles become difficult to control. Haul road conditions (including loading and dumping areas) must be checked to determine whether they are acceptable and ideally suited to the operation, that is, the geometric, structural and functional designs are to standard, together with the correct operating practices.

Haul road design is a stronger factor affecting the empty and full haul cycle times. Wet material $4-6 \mathrm{~m}$ beneath the road can be easily transformed into a very thick liquid like state by vibrations caused by fully loaded trucks, and cause delays for both full and empty haul operations. A gentle slope from the centre of the haul road helps to drain the rain water away from the road. To enhance and speed up truck cycle time, haul roads should be regularly maintained, especially soft areas (undulation) leading to wet spots on the road. Despite the extended cycle time, haul road undulation may cause damage to truck tyres and suspension system of the trucks.

\subsection{Analysis of Hanging and Spotting Time Data}

Since these two operations take place when the truck is empty, the two cycle time components are not related to material being hauled, tonnage loaded and haul road, instead the cycle time depends on site design, excavator-truck design features and driver's experience. Using data collected for one month for all trucks and excavators ( $N=60,690$ data points), the average spotting and hanging times were observed to be 57.6 and 112.2 seconds, respectively, with hanging time being longer than spotting time. Stronger variability was observed for hang time than spotting time, with $\sigma_{h g}=496.3$ seconds and $\sigma_{s p}=73$ second, respectively. The flatter PDF for hand time data compared to the spotting time data signifies the higher variability and standard deviation observed. Moreover, the hang time data is more skewed than spotting time data, with $S_{k}=26.6$ and 5.4, respectively, as revealed by high frequency values of $t_{h g}$ around 1000 seconds compared to spotting time. The PDFs were both logarithmic in nature (as shown in Figure 10) although their shapes and tails are different.

The variability during spotting is caused mainly by technique used for loading such as spotting for top loading at $45^{\circ}, 90^{\circ}$, etc. There is extended time during spotting because the truck driver must wait until the excavator operator has spotted the bucket in the correct position. That is, this process depends not only on the location or site design, excavator and truck design, but also on the two drivers' decisions. Further research can be conducted to establish the variations in $t_{h g}$ and $t_{s p}$ on excavator models, locations, and excavator-truck combinations.

\subsection{Total Cycle Time Analysis}

The production capacity data for the waste material transportation system was established using Equation (5), with loaded tonnage, $L_{i}=33$ metric tons, for waste NAF, at varying total cycle time, $T_{c t}$ (determined using Equation (4)). The 

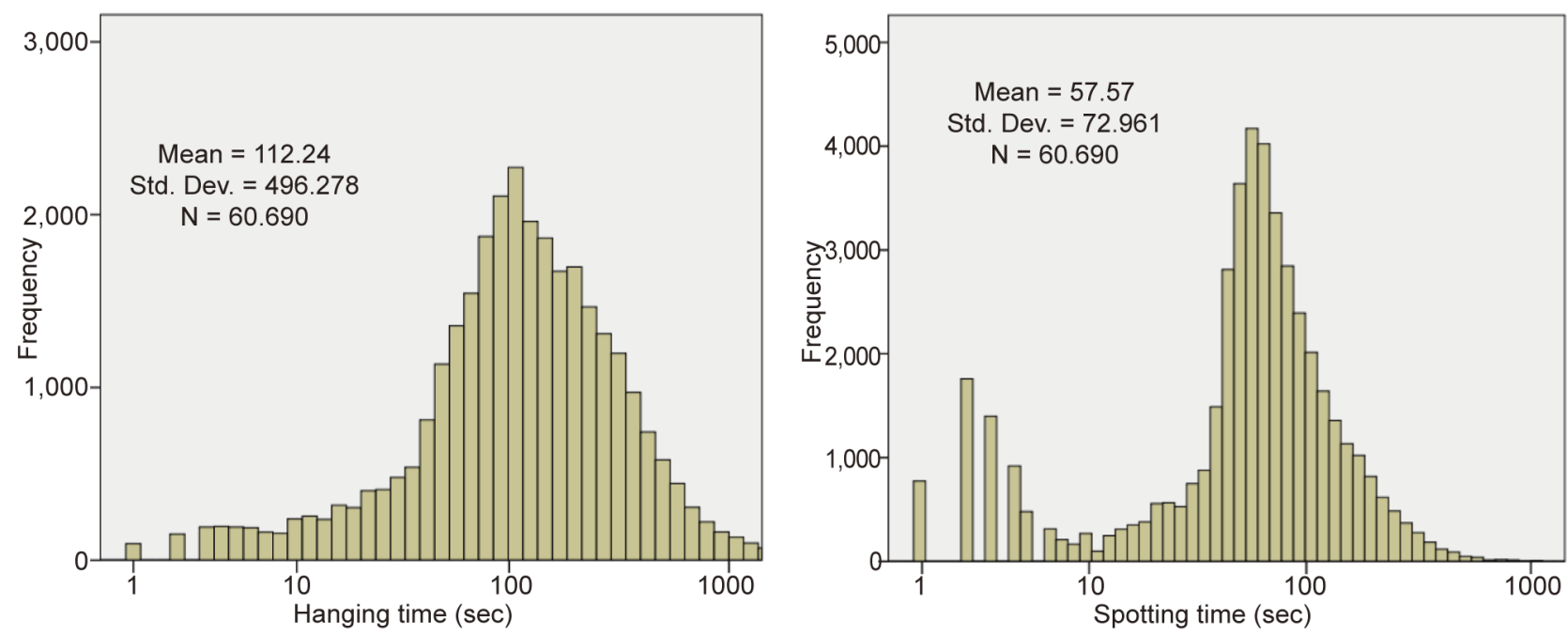

Figure 10. Histograms of hanging and spotting time data during material transportation in an open-pit mine.

total cycle time depends on haul road length and conditions, tonnage loaded, truck model and capacity (speed in this case), driver's decisions, number of trucks per excavator, etc. By fixing all other factors, Figure 11 compares the total cycle time data for different trucks and from different locations (3 locations at GHW2 and one location at LCC1). For DT100 series trucks, the values of $T_{c t}$ were observed to drop for a location denoted as LCC1 attributable to differences in distance or haul road conditions compared to GHW2 locations. For DT200 series trucks loaded with $30 \mathrm{t}$ of Waste PAF, there was no trend attributable to differences in distances from excavator to dumpsites.

Figure 12 shows the PDF of the total cycle time for waste material transportation system, comprising of all seven steps of material transport operation. The total cycle time ranged from 400 to 6000 seconds, with $N=32,543$ data points loaded with $33 \mathrm{t}$ of Waste NAF. The average value was estimated to be $1300 \mathrm{sec}$, with stronger variations depicted by high standard deviation $(\sigma=737.1 \mathrm{sec})$. In the past, in both theory and practice, increased attention was focused on the level of machine capacity utilization because machines were costly and thus had a greater impact on production efficiency. However, emphasis is currently on material transport efficiency since efficient machines are currently available in the market.

Figure 12 shows also the PDF of production capacity data corresponding to the same Waste NAF loading at $33 \mathrm{t}$. The average production capacity was 2632 $t /$ day. With the overall average cycle time of 1300 seconds to transport $33 \mathrm{t}$ of Waste NAF from an excavator location to the waste dump and using Equation (5), the corresponding daily production capacity is estimated to be $2193 \mathrm{t}$ waste material per day.

\subsection{Analysis of the Total Cycle Time Components}

Figure 13 shows the distribution of the delay times for the components of the total cycle time, when the same type of material is loaded (that is, Waste NAF) at 

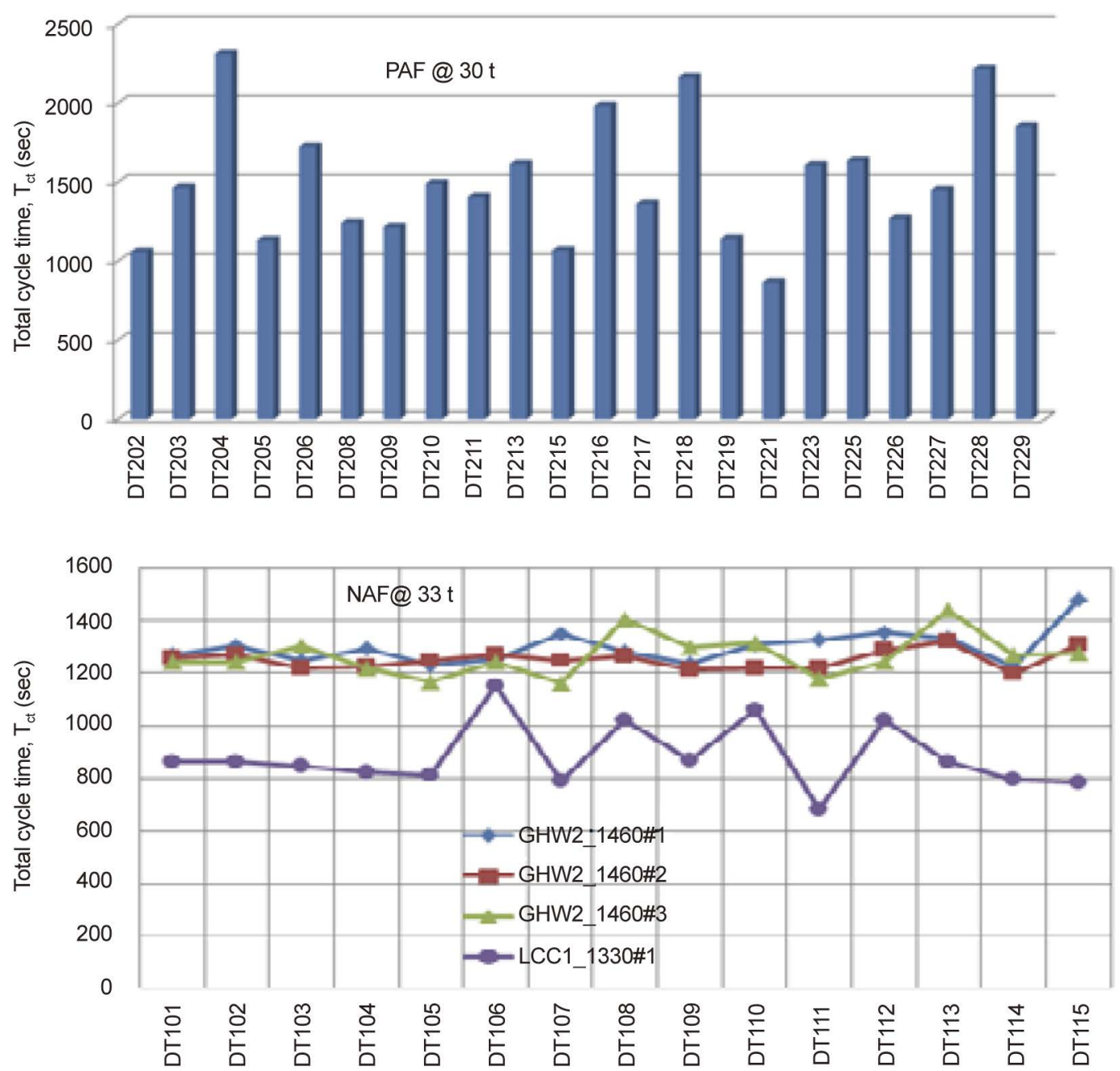

Figure 11. Comparison between average total cycle time values for different trucks (a) loaded with the same material and fixed tonnage (Waste PAF, $30 \mathrm{t}$ for DT200), and (b) data from different locations (for DT100).
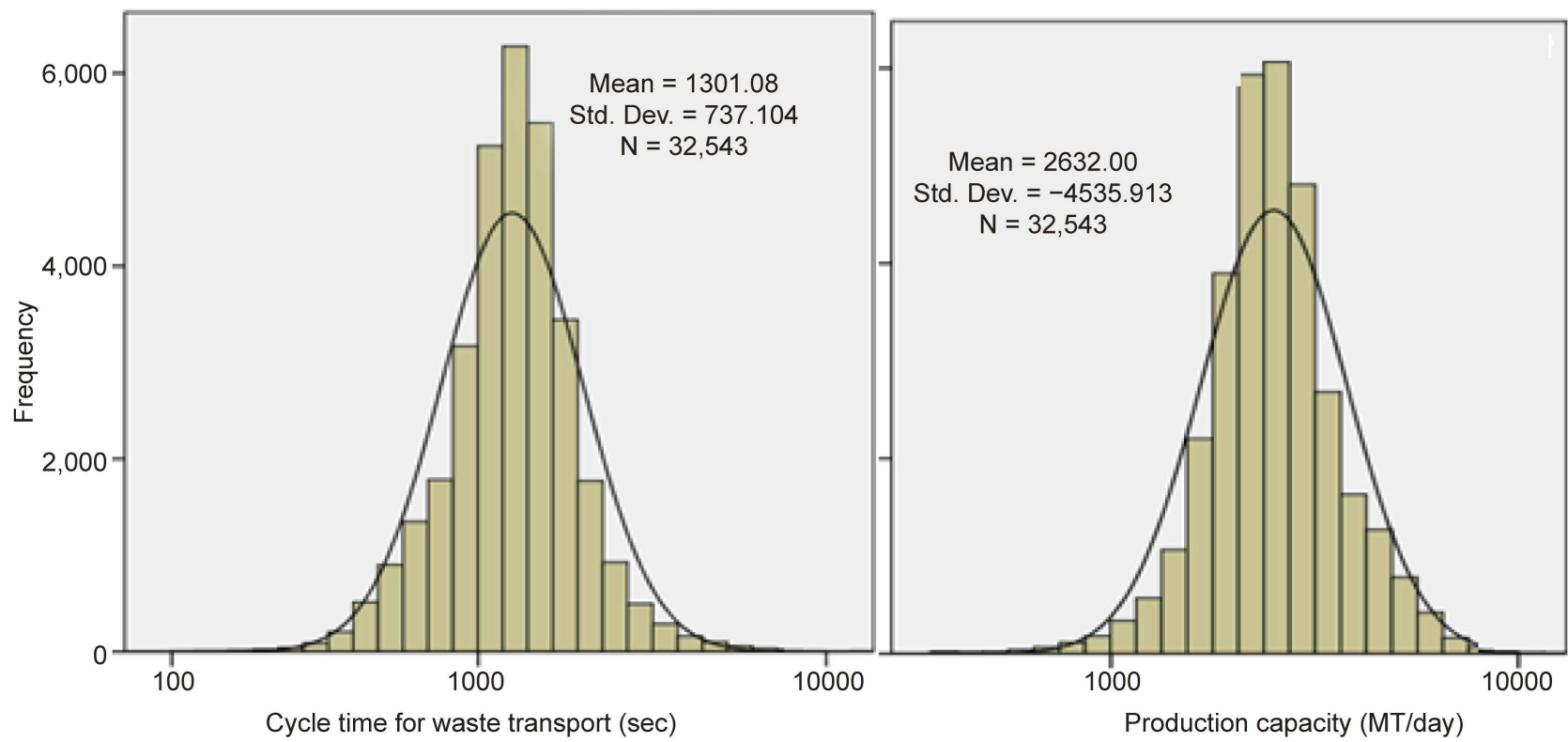

Figure 12. PDFs of the total cycle time and production capacity during Waste NAF transportation. 


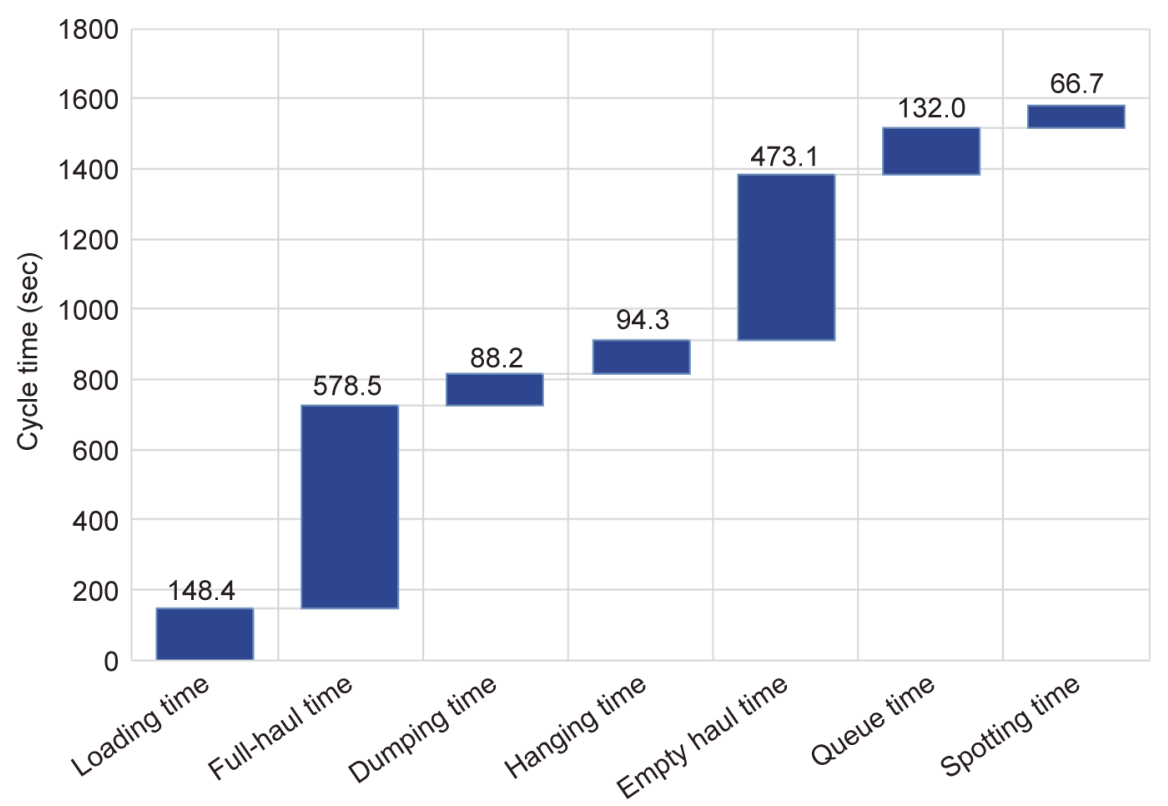

Figure 13. Average cycle time for the seven components of Waste NAF transportation process in an open pit mine.

the same tonnage of $33 \mathrm{t}$. Full haul time was observed to be the longest among the seven components (as expected when such a large quantity of material being hauled) that is, 578.5 seconds, followed by empty haul time with average of 473.1 seconds. Due to large number of trucks being loaded by a small number of excavators, trucks took longer times waiting to be loaded leading to queue time of 132.0 seconds on average. The hanging time after dumping the waste materials took 94.3 seconds on average, with the shortest time being the spotting time which took 66.7 seconds on average. In terms of percent of total cycle time, the full haul was about $44.5 \%$, while empty-haul was about $36.4 \%$

It should be noted that the total cycle time variations are attributable to the consequences of deterministic factors affecting each component. The machine utilization capacity (for both trucks and excavators) can be increased by eliminating bottlenecks (or unnecessarily extended cycle times). Other production cycle time components are affected by a number of factors that are human-related, which are stochastic in character, but controllable.

The hanging, queuing and spotting operational delays contributed to about $18.5 \%$ of the total cycle time (for the case presented in Figure 13). Although the average times for hanging, queuing and spotting were the shortest, the combined total time impacts the mine operations significantly. The total cycle time, based on the average values (for Waste NAF loaded at $33 \mathrm{t}$ ) was equal to 1,581 seconds leading to a production capacity of $1803 \mathrm{t} /$ day. However, if the queuing time ( $8.3 \%$ of total cycle time) can be eliminated, the production capacity could rise to $1,968 \mathrm{t}$ of waste NAF per day (that is, $9.15 \%$ increase). Hang time, also known as "wait on truck" time, is experienced by a loading unit verses the time lost by the trucks while queuing. The average hang cycle time was 94.3 seconds or $6.0 \%$ of the total cycle time. 
Figure 14 shows the Pareto chart for the cycle time components during Waste NAF transportation. Results show that the three most critical components or bottlenecks of the waste transportation system were identified as full-haul (44.5\%), empty-haul (36.4\%) and loading processe (11.4\%), which forms mine operation KPIs. Thus, cycle time reduction should focus at these three components which can be reduced by managing drivers' behavior, good haul road design and improved drilling and blasting efficiency to allow faster loading.

\subsection{Analysis of the Productive Fraction of the Total Cycle Time}

The productive time, also called theoretical time, comprised of loading, full haul and dumping time (also called value-added activities), as shown in Equation (6). On the other hand, non-productive time involved operations related to empty haul, hanging, spotting and queuing at the excavator as per Equation (7). The productive time component was used to judge the effectiveness of a given material transportation system. The spans of the productive and non-productive time delays are shown in the PDFs in Figure 15.

The average productive time $\left(T_{t h}=662.1 \mathrm{sec}\right)$ was observed to be slightly higher than the non-productive time ( $\left.T_{n p}=639 \mathrm{sec}\right)$. On average, the total cycle time is $54 \%$ productive, while the rest comprise of activities which are nonproductive. However, the $T_{n p}$ is still too high, which requires implementation of cycle time reduction strategies. In terms of variability, the non-productive times vary too wide from one dispatch to another with high standard deviation $\left(\sigma_{n p}=\right.$ $681 \mathrm{sec})$ compared to the productive time $\left(\sigma_{t h}=241 \mathrm{sec}\right)$. Although non-productive time is highly skewed to the right $\left(S_{k}=16.0\right)$ compared to the productive time $\left(S_{k}=6.615\right)$, the average values of two components of the total cycle time are almost equal. The plot shows also that there are many data points beyond 1000 seconds for non-productive time than on the productive time. Figure 15 shows also that the probability distributions of the productive and non-productive times data are similar.

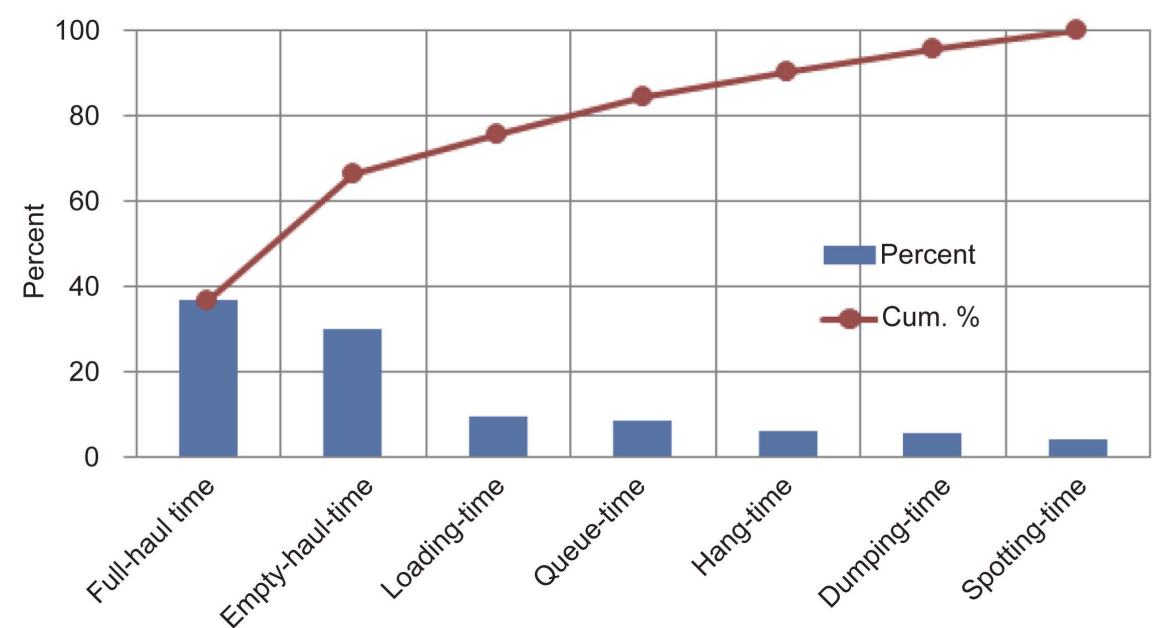

Figure 14. Pareto chart for the total cycle time components during Waste NAF transportation in an open-pit mine. 

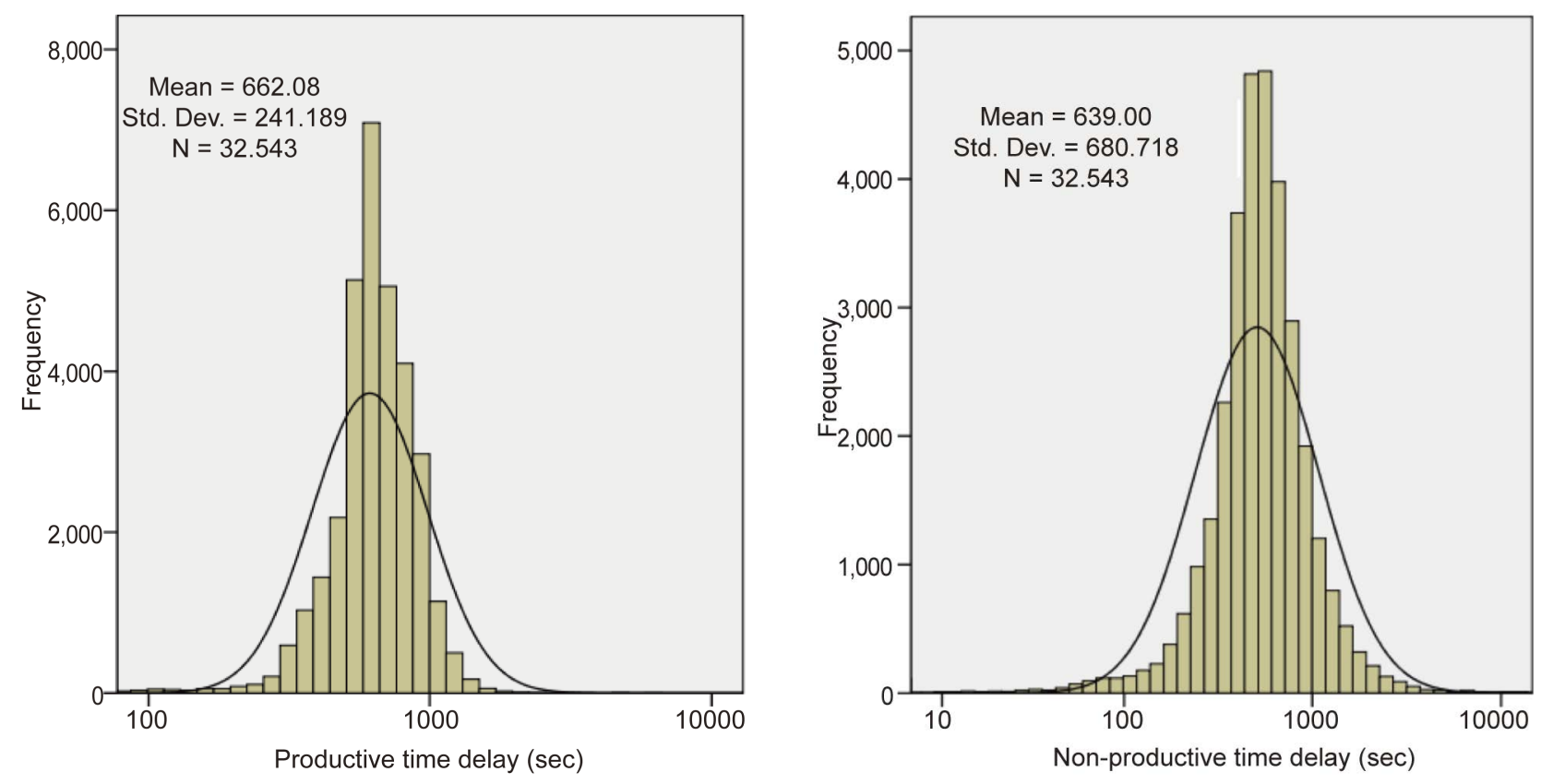

Figure 15. Probability distributions of the productive and non-productive time delays during waste NAF material transportation.

\subsection{Analysis of Cycle Time Performance Ratio}

Figure 16 shows the probability density function of the CTPR values for Waste NAF transportation system. The variability in performance ratio, that is, inconsistence or non-optimized performance, was assessed by using the probability density function of the $T_{p r}$ values with $N=32,539$ data points collected in one month (as shown in Figure 16). The mean value of $T_{p r}$ was observed to be 2.423, which is higher than the target value of $T_{p r}=1.0$, indicating that performance of the waste transportation system was poor in the open pit mine. Most of the $T_{p r}$ data are far above 1.0, indicating poor performance, based on cycle time performance analysis. The strong variations in $T_{p r}$ as depicted by higher values of standard deviation $(\sigma=8.67)$ is an indication of poor performance caused by inconsistence between cycles. Furthermore, there was a higher tendency of high values of $T_{p r}$ up to 10.0 observed at decreasing frequency, supported also by higher value of positive skewness $\left(S_{k}=52.8\right)$.

\subsection{Detailed Analysis of the PDFs from Material Transport Data}

Table 4 summarizes the analysis of PDF types of the cycle time components observed in this study. It can be seen from Table 4 that the PDFs for loading process were different in nature from those of the rest of the seven steps of material transportation cycle. This can be attributed to the fact that this step involves a different machine and different driver from the truck (that is, the excavator), operations and characteristics of which differ from the truck. Together with data presented in Table 4, further analysis revealed that the PDFs of total cycle time, production capacity, productive time delay, non-productive time fraction and cycle time performance ratio were logarithmic in nature while the productive time fraction data gives a linear PDF. 


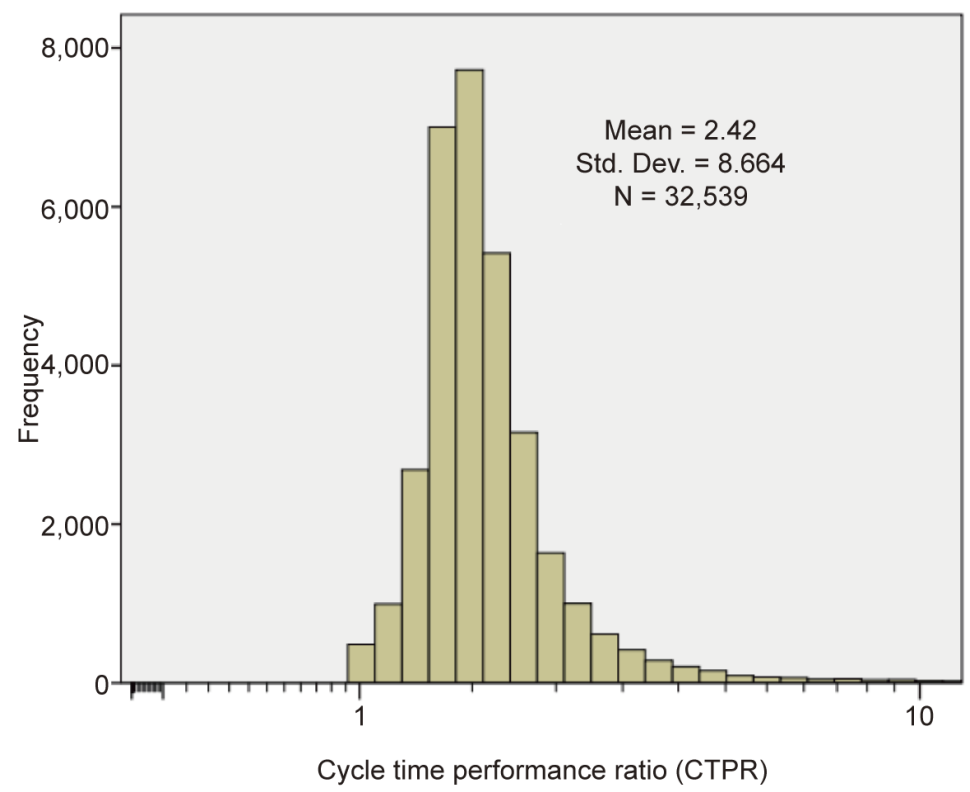

Figure 16. Probability density function for cycle time performance ratio (CTPR) during Waste NAF transportation.

Table 4. Characterizing PDFs of cycle time data for major components of the material transport operations.

\begin{tabular}{|c|c|c|c|}
\hline Data source & PDF scaling $\mathrm{t}$ & \multicolumn{2}{|c|}{ Fitting using Kolmogorov-Smirnov statistics } \\
\hline Queuing time & Logarithmic & Laplace & $\lambda=0.00538 ; \mu=164.04$ \\
\hline Spotting time & Logarithmic & Wakeby & $\begin{array}{l}\alpha=124.32 ; \beta=1.1658 ; \gamma=8.8084 \\
\delta=0.55764 ; \xi=-9.2277\end{array}$ \\
\hline Loading time & Linear & Wakeby & $\begin{array}{l}\alpha=1472.3 ; \beta=12.48 ; \gamma=44.252 \\
\delta=0.09683 ; \xi=-20.843\end{array}$ \\
\hline Full haul time & Logarithmic & Cauchy & $\sigma=105.44 ; \mu=908.18$ \\
\hline Dumping time & Logarithmic & Wakeby & $\begin{array}{l}\alpha=173.21 ; \beta=1.383 ; \gamma=16.627 \\
\delta=0.44645 ; \xi=-9.7789\end{array}$ \\
\hline Hanging time & Logarithmic & Gumbel Min & $\sigma=198.48 ; \mu=180.95$ \\
\hline Empty haul time & Logarithmic & Wakeby & $\begin{array}{l}\alpha=2977.6 ; \beta=4.5719 ; \gamma=165.41 ; \\
\delta=0.38745 ; \xi=-121.64\end{array}$ \\
\hline
\end{tabular}

\section{Conclusions}

\section{Based on this study, it can be concluded that:}

The Waste NAF and PAF were the major rock types generated and loaded and transported at highest rate in an open pit mine (64\% and $17 \%$ of the total material hauled), out of a total of 1.73 million tons per month. Due to low truck utilization efficiency caused by under-loading, the average tons per dispatch, $T_{d p}$, ranged from as low as 15.8 to 32.6 , with more than $43 \%$ of the trucks being severely under-loaded below $10 \%$. The dumping cycle times, $T_{d p}$, were strongly affected by material types than changes in location or trucks.

Based on a maximum loading of 33 tons, the truck fill factor, $f$, varied from 1.0 to 0.3 and varied also with waste rock types. Moreover, the maximum fill factor, 
$f=1.0$ was observed at a highest frequency of $61.2 \%$ while the higher value $f=$ 0.91 was observed for only $20.5 \%$ of the dispatches. The other fill factor values ( $f$ $=0.81,0.23$ and 0.18 ) were, however, observed at lower occurrences (below $10 \%)$. Up to $59.5 \%$ of the dispatches for truck loading involved queuing at the excavators, with an average queuing time, $t_{q}$, of 124.1 seconds when $33 \mathrm{t}$ of Waste NAF were being loaded into various trucks. Despite the lower average values of $t_{q}$ (based on $33 \mathrm{t}$ of Waste NAF loaded) and also on individual excavators ( $t_{q}=102-201$ seconds), larger values of $t_{q}$ up to 1000 seconds were observed (indicating wider span of queuing time). Since trucks form ques while idling, a cycle time reduction effort to minimize operations cost was recommended.

The loading cycle time, $L_{t}$ varied less between Waste PAF and NAF when $30 \mathrm{t}$ were loaded, PDFs of which were linear, spanning up to 400 seconds with low positive skewness. On average, values of $L_{t}$ ranged between 134 and 141 seconds, which are low indicating effective loading process. The average dumping times, $t_{d}$ for $30 t$ were 93 and 116 seconds for Waste PAF and NAF, respectively, which are shorter compared to loading cycle times. The $t_{d}$ increased with tonnage dumped for a fixed material type, while the PDFs of $t_{d}$ data were logarithmic, different from those of $L_{t}$

Although shorter than full-haul time, on average, the empty-haul time varied widely than the former (with higher standard deviation). The two processes comprised the largest part of the total cycle time, necessitating closer monitoring of drivers' behavior and haul road conditions to minimize the non-productive component. With exception of loading cycle time data and the productive time fraction data, the rest of the data sets exhibited logarithmic PDFs.

The total cycle time for materials transport process, $T_{c b}$ varied by trucks and location (or haul distances) when the same material was loaded and hauled at the same tonnage between excavators and dumpsites. The average value of $T_{c t}$ was about 1,301 seconds corresponding to an average production capacity, $P_{c p}$, of 2,632 t/day for hauling $33 \mathrm{t}$ of Waste NAF. The PDFs of $T_{c t}$ and $P_{c p}$ data were also logarithmic.

Based on Pareto analysis of $T_{c t}$ components, three bottlenecks were identified for the material transport system in an open pit mine, that is: full-haul, empty haul and loading operations, which require attention. The productive component of the total cycle time, $T_{t h}$, was determined to be 662.1 seconds, being $54 \%$ of the total cycle time on average. Reducing the non-productive component, $T_{n p}$, will improve the productivity and performance of the waste transportation system in the open pit mine. Analysis of the cycle time performance ratio $\left(T_{p r}\right)$ shows that the mean value was 2.423 , closer to 1.0 while ranging up to 10 , with high positive skewness, indicating that the performance of the waste rock transportation system in an open pit mine was poor.

\section{Acknowledgements}

The author is grateful to the Management Geita Gold Mine (GGM), Tanzania, for permission to conduct this study and providing the technical assistance dur- 
ing data collection.

\section{References}

[1] Alarie, S. and Gamache, M. (2002) Overview of Solution Strategies Used in Truck Dispatching Systems for Open Pit Mines. International Journal of Surface Mining, $16,59-76$.

[2] Blouin, S., Guay, M. and Rudie K. (2007) An Application of Discrete-Event Theory to Truck Dispatching. Central European Journal of Operational Research, 15, 369-391. https://doi.org/10.1007/s10100-007-0037-8

[3] Kheiryeh, E. and Osanloo, M. (2012) The Optimal Dispatching Station Site Selection Effective Factor in Open Pit Mines. Proceedings of 21 st Int. Symp. on Mine Planning and Equipment Selection (MPES), New Delhi, 28-30 November 2012, 360-372.

[4] Ercelebi, S.G. and Bascetin, A. (2009) Optimization of Shovel Truck System for Surface Mining. Journal of the Southern African Institute of Mining and Metallurgy, 109, 433-439.

[5] Chanda, E.K. and Gardner, S. (2010) A Comparative Study of Truck Cycle Time Prediction Methods in Open-Pit Mining. Engineering, Construction and Architectural Management, 17, 446-460. https://doi.org/10.1108/09699981011074556

[6] Rustan, A. and Nie, S. (1992) New Method to Test Rock Breaking Properties of Explosive in Full Scale. International Journal of Mining and Environment, 6, 191-200.

[7] Kun-Jen, C., Kuo-Lung, H. and Shaw-Ping, L. (2009) The Optimal Production Cycle Time in an Integrated Production-Inventory Model for Decaying Raw Materials. Applied Mathematical Modeling, 33, 1-10. https://doi.org/10.1016/j.apm.2007.10.010

[8] Ta, C.H., Kresta, J.V., Forbes, J.F. and Marquez, H.J. (2005) A Stochastic Optimization Approach to Mine Truck Allocation. International Journal of Mining, Reclamation and Environment, 19, 162-175. https://doi.org/10.1080/13895260500128914

[9] Agrawal, A., Minis, I. and Nagi, R. (2000) Cycle time reduction by improved MRP-Based Production Planning. International Journal of Production Research, 38, 4823-4841. https://doi.org/10.1080/00207540050205659

[10] Tzu-Hsien, L. (2009) Optimal Production Run Length and Maintenance Schedule for a Deteriorating Production System. The International Journal of Advanced Manufacturing Technology, 43, 959-963.

https://doi.org/10.1007/s00170-008-1773-1

[11] Giri, B.C. and Yun, W.Y. (2005) Optimal Lot Sizing for an Unreliable Production System under Partial Backlogging and at Most Two Failures in a Production Cycle. International Journal of Production Economics, 65, 229-243. https://doi.org/10.1016/j.ijpe.2004.01.004

[12] Rappold, J. and Yoho, K.D. (2008) A Model for Level-Loading Production in the Process Industries when Demand is Stochastic. Production Planning \& Control, 19, 686-701. https://doi.org/10.1080/09537280802573726

[13] Taleizadeh, A.A., Sadjadi, S.J. and Akhavan Niaki, S.T. (2011) Multiproduct EPQ Model with Single Machine, Backordering and Immediate Rework Process. European Journal of Industrial Engineering, 5, 388-411.

https://doi.org/10.1504/EJIE.2011.042738

[14] Krzyzanowska, J. (2007) The Impact of Mixed Fleet Hauling on Mining Operations at Venetia Mine. The Journal of the South African Institute of Mining Metallurgy, 107, 215-224. 
[15] Erdem, B., and Kormaz, F. (2012) Analysis of Dragline Cycle Time Components. Journal of Mining Science, 48, 545-558. https://doi.org/10.1134/S1062739148030185

[16] Johnson, J.D. (2003) A Framework for Reducing Manufacturing Throughput Time. Journal of Manufacturing Systems, 22, 283-298. https://doi.org/10.1016/S0278-6125(03)80009-2

[17] Li, L., Chang, Q., Ni, J. and Biller, S. (2009) Real Time Production Improvement through Bottleneck Control. International Journal of Production Research, 47, 6145-6158. https://doi.org/10.1080/00207540802244240

[18] Lati, N. and Gilad I. (2010) Minimizing Idle Times in Cluster Tools in the Semiconductor Industry. International Journal of Production Research, 48, 6443-6459. https://doi.org/10.1080/00207540903280556

[19] Patti, A.L. and Watson K.J. (2010) Downtime Variability: the Impact of Duration-Frequency on the Performance of Serial Production Systems. International Journal of Production Research, 48, 5831-5841. https://doi.org/10.1080/00207540903280572

[20] Schultz, C.R. (2004) Spare Parts Inventory and Cycle Time Reduction. International Journal of Production Research, 42, 759-776. https://doi.org/10.1080/00207540310001626210

[21] Kusar, J., Berlec, T., Zefran, F., Starbek, M. (2010) Reduction of Machine Setup Time. Strojniškivestnik - Journal of Mechanical Engineering, 56, 833-845.

[22] Berlec, T., Govekar, E., Grum, J., Potocnik, P. and Starbek, M. (2008) Predicting Order Lead Times. Strojniškivestnik - Journal of Mechanical Engineering, 54, 308-321.

[23] Jeong, K.Y. and Phillips, D.T. (2001) Operational Efficiency and Effectiveness Measurement. International Journal of Operations and Production Management, 21, 1404-1416. https://doi.org/10.1108/EUM0000000006223

[24] Rai, P. (2004) Performance Assessment of Draglines in Open Cast Mines. Indian Journal of Engineering \& Material Science, 11, 493-498.

[25] Rai, P., Yadav, U. and Kumar, A. (2011) Productivity Analysis of Draglines Operating in Horizontal Tandem Mode of Operation in Coal Mine: A Case Study. Geotechnical and Geological Engineering, 29, 493-504. https://doi.org/10.1007/s10706-011-9398-9

[26] Mohammadi, M., Rai, P., Oraee, K. and Kumar, M. (2013) Analysis of Availability and Utilization of Dragline for Enhancement of Productivity in Surface Mines-A case study. Proceeding of 23rd World Mining Congress, Montreal, Paper No. 598.

[27] Ko, S.S., Serfozo, R. and Sivakumar, A.I. (2004) Reducing Cycle Times in Manufacturing and Supply Chains by Input and Service Rate Smoothing. IIE Transactions, 36, 145-153. https://doi.org/10.1080/07408170490245441

[28] Sanders, R. (1987) The Pareto Principle: Its Use and Abuse. Journal of Services Marketing, 1, 37-40. https://doi.org/10.1108/eb024706

[29] Elbeltagi, I., Kempen, T. and Garcia, E. (2014) Pareto-Principle Application in nonIT Supported CRM Processes: A Case Study of a Dutch Manufacturing SME. Business Process Management Journal, 20, 129-150. https://doi.org/10.1108/BPMJ-05-2012-0043

[30] Kangonji, I.S. and Manyele, S.V. (2016) Analysis of Health Workers' Perceptions on Medical Waste Management in Tanzanian Hospitals. Engineering Journal, 8, 445459.

[31] Osanloo, M. and Hekmat, A. (2005) Prediction of Shovel Productivity in the GoleGohar Iron Mine. Journal of Mining Science, 41, 177-184. 
https://doi.org/10.1007/s10913-005-0081-5

[32] Barbaro, R. and Rosenshine, M. (1987) Evaluating the Productivity of a ShovelTruck Materials Haulage System Using a Cyclic Queuing Model. AIME Transactions, 282, 1824-1827.

Submit or recommend next manuscript to SCIRP and we will provide best service for you:

Accepting pre-submission inquiries through Email, Facebook, LinkedIn, Twitter, etc. A wide selection of journals (inclusive of 9 subjects, more than 200 journals)

Providing 24-hour high-quality service

User-friendly online submission system

Fair and swift peer-review system

Efficient typesetting and proofreading procedure

Display of the result of downloads and visits, as well as the number of cited articles Maximum dissemination of your research work

Submit your manuscript at: http://papersubmission.scirp.org/

Or contact eng@scirp.org 